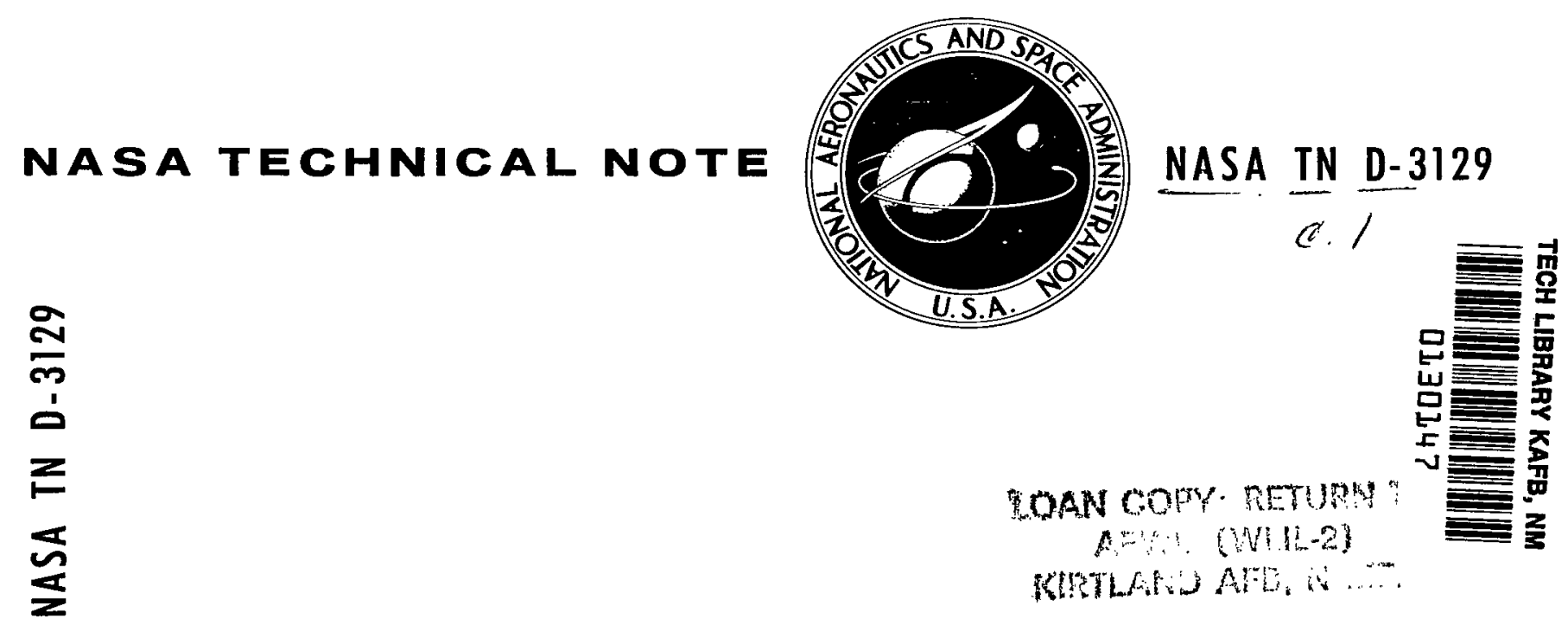

\title{
OPERATING PARAMETERS OF THE OMEGATRON MASS SPECTROMETER IN ULTRAHIGH VACUUM
}

by James M. Bradford, Jr. Langley Research Center Langley Station, Hampton, Va.

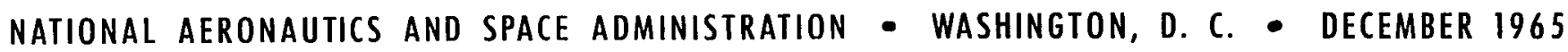


NASA TN D-3129

\section{OPERATING PARAMETERS OF THE OMEGATRON MASS}

\section{SPECTROMETER IN ULTRAHIGH VACUUM}

By James M. Bradford, Jr.

Langley Research Center

Langley Station, Hampton, Va.

\section{NATIONAL AERONAUTICS AND SPACE ADMINISTRATION}

For sale by the Clearinghouse for Federal Scientific and Technical Information

Springfield, Virginia 22151 - Price $\$ 2.00$ 
CONTEINTS

Page

SUMMARY . . . . . . . . . . . . . . . . . . . . . . . . . 1

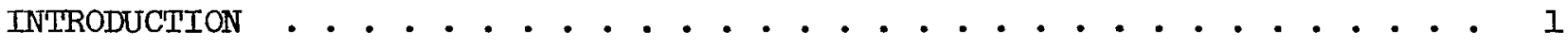

SYMBOLS . . . . . . . . . . . . . . . . . . . . . . . . 2

DESCRIPTION OF THH OMEGATRON

PRINCIPLE OF OPERATION AND THEORY . . . . . . . . . . . . . . . . . . 3

DESCRIPTION OF APPARATUS . . . . . . . . . . . . . . . . . . . . 4

PROCEDURE . . . . . . . . . . . . . . . . . . . . . . . . . . . 5

Cleaning Omegatron Tube and Magnet Alinement . . . . . . . . . . . . 5

Pressure Measurement . . . . . . . . . . . . . . . . . . . 6

Gas Inlet Manifold . . . . . . . . . . . . . . . . . . . . . 6

Test Procedure . . . . . . . . . . . . . . . . . . . . . 7

ACCURACY . . . . . . . . . . . . . . . . . . . . . . . . 8

Omegatron Power Supply . . . . . . . . . . . . . . . . . . . 8

$\mathrm{RF}$ Oscillator . . . . . . . . . . . . . . . . . . . . . . . . 8

Magnet . . . . . . . . . . . . . . . . . . . . . . . . . . 9

Electrometer . . . . . . . . . . . . . . . . . . . . . . . . 9

Pressure Measurement . . . . . . . . . . . . . . . . . . . . 9

RESULTS AND DISCUSSION . . . . . . . . . . . . . . . . . . . . . . . 9

General . . . . . . . . . . . . . . . . . . . . . . . . . . . 9

Variation of Ion Current With Trap Voltage . . . . . . . . . . . . . 10

Variation of Ion Current With Electron Collector Voltage . . . . . . . 10

Variation of Ion Current With RF Voltage . . . . . . . . . . . . . . . . 11

Variation of Ion Current With RF Voltage, Electron Collector

Voltage, and Trap Voltage at Various Emission Currents . . . . . . . . 11

Sensitivity . . . . . . . . . . . . . . . . . . . . . . . 12

Resolution ............................. . 14

Comparison of Theoretical and Measured Cyclotron Frequencies . . . . . 14

Comparison of the Operating Parameters for Two Omegatron Tubes . . . . 14

CONCLUSIONS . . . . . . . . . . . . . . . . . . . . . . . . 15

APPENDIX - REIATION BETWEEN SOME OF THE PARAMEIHRS OF THE OMEGATRON • • • 17

REFERENCES . . . . . . . . . . . . . . . . . . . . . . 20

TABLES .............................. . . . . . . . . . .

FIGURES . . . . . . . . . . . . . . . . . . . . . . . . 23 


\title{
OPERATING PARAMETERS OF THE OMEGATRON MASS
}

\author{
SPECIROMETER IN ULTRAHIGH VACUUM \\ By James M. Bradford, Jr. \\ Langley Research Center
}

\section{SUMMARY}

The operating parameters of the omegatron to give the maximum sensitivity were determined for helium, nitrogen, argon, and carbon dioxide for pressures from about $7 \times 10^{-10}$ torr to $7 \times 10^{-7}$ torr. The recommended values were 0.7 volt for the trap voltage, 8 volts for the electron collector voltage, and 1.5 volts rms for the RF voltage while using an emission current of $1 \mu A$ and an electron bias voltage of 70 volts. There is, further, a range of values for each of the operating parameters in which the sensitivity is not a strong function of the operating parameter in question.

The sensitivity of the omegatron was determined to be 1.2 torr ${ }^{-1}$ for helium, 7.5 torr $^{-1}$ for nitrogen, 11.3 torr $^{-1}$ for argon, and 17.0 torr-1 for carbon dioxide.

The operating parameters and sensitivity for a second omegatron tube were determined and were essentially the same as for the first tube.

\section{INTRODUCTION}

In most experiments conducted in the ultrahigh vacuum range it is essential to know the partial pressure of each gas surrounding the experiment. In working with so-called "clean surfaces," for instance, it is necessary to know which gases are adsorbing on the clean surface. As a more general example, if an ionization gage is used to measure the pressure, the composition of the gas must be known because an ionization gage has a different sensitivity for each gas. One instmment that will give a quantitative as well as qualitative analysis of the gases in the ultrahigh vacuum range is the omegatron.

The omegatron was first proposed by Hipple, Sommer, and Thomas in reference 1 as a device for accurately determining the value of the faraday. A later paper by these authors (ref. 2) showed that the omegatron could be used to measure the mass-to-charge ratio of gases present in a vacuum system. One of the earliest applications of the omegatron as a partial-pressure analyzer was by Alpert and Buritz (ref. 3). They utilized a simplified version of the omegatron to show that helium was the predominant residual gas in their glass 
ultrahigh-vacuum system. Many authors (refs. 4, 5, and 6) since then have investigated different configurations of the omegatron in the pressure range around $10^{-6}$ torr and some investigations have even been made to about $10^{-8}$ torr (refs. 7, 8, and 9). Very little work, however, has been done to investigate the operating parameters of the omegatron in the pressure range below $10^{-8}$ torr. It is the purpose of this paper to define these parameters in the vacuum range from 10-7 to below 10-10 torr and to determine the sensitivity of the omegatron for certain gases (helium, argon, nitrogen, and carbon dioxide) in this pressure range. If the operating parameters and sensitivity are constant throughout this pressure range and for these gases, the omegatron can be used with more assurance as a quantitative as well as qualitative analyzer. This investigation was conducted on a simplified version of the omegatron based on the design of Alpert and Buritz (ref. 3) which is commercially available. Some of the data presented herein has been published in reference 10.

\section{SYMBOLS}

Some of the physical quantities defined in this paper are given both in the U.S. Customary Units and in the International System of Units, (SI). The factors relating these two systems of units are presented in reference 11.

B

$E$

$\mathrm{E}_{\mathrm{O}}$

e

$f_{c}$

$I_{C}$

$\mathrm{I}_{\mathrm{E}}$

$\mathrm{M}$

m

$\mathrm{n}$

$\mathrm{P}$

$\mathrm{R}$

$r$ magnetic flux density, gauss

strength of alternating electric field, electromagnetic units

electric field strength, volts per centimeter

electron charge, electromagnetic units

cyclotron frequency, cycles per second (see eq. (10))

ion current, amperes

emission current, amperes

ion mass, atomic mass units

ion mass, grams

number of turns made by resonant ion prior to being collected (see eq. (II))

pressure in vacuum system, torr

resolution (see eq. (8))

radius of ion orbit, centimeters (see eq. (1)) 


$\begin{array}{ll}r_{\mathrm{O}} & \text { radial distance from electron beam to ion collector, centimeters } \\ r_{\mathrm{t}} & \text { radius of resonant-ion orbit at time } t \text {, centimeters (see eq. (4)) } \\ \mathrm{S} & \text { sensitivity, torr }-1 \text { (see eq. (13)) } \\ t & \text { time after ion is formed, seconds } \\ t_{\mathrm{O}} & \text { time for resonant ion to reach radius } r_{\mathrm{O}} \text {, seconds } \\ \mathrm{V}_{\mathrm{B}} & \text { electron bias voltage, volts } \\ \mathrm{V}_{\mathrm{E}} & \text { electron collector voltage, volts } \\ \mathrm{V}_{\mathrm{F}} & \text { voltage across filament, volts } \\ \mathrm{V}_{\mathrm{R}} & \text { RF voltage from RF oscillator, volts rms } \\ \mathrm{V}_{\mathrm{T}} & \text { trap voltage, volts } \\ \lambda & \text { path length of resonant ion, centimeters (see eq. (12)) } \\ \omega & \text { angular frequency of electric field, radians per second } \\ \omega_{\mathrm{C}} & \text { cyclotron angular frequency, radians per second (see eq. (3)) }\end{array}$

DESCRIPTION OF THE OMEGATRON

The physical arrangement of the electrodes inside the omegatron tube is shown in figure 1 . The dimensions were furnished by the manufacturer. The sides of the ionization chamber form the sides of a 2 -centimeter cube with holes in two opposing sides to permit passage of the ionizing electron beam. The electron-beam focus electrode and the electron collector are 0.005-inchthick $(0.013 \mathrm{~cm})$ molybdenum sheet, 12 millimeters square. The electron-beam focus electrođe has a 0.025 -inch-diameter $(0.064 \mathrm{~cm})$ hole in the center to permit passage of the electron beam. The filament is 0.0035 -inch-diameter $(0.0089 \mathrm{~cm})$ tungsten wire, is 12 millimeters long, and is positioned 1 millimeter in front of the electron focus electrode. The magnetic field indicated in figure I comes from a 3980-gauss ( 0.3980 tesla) permanent magnet which is external to the omegatron tube. A photograph of the omegatron tube is shown as figure 2 .

\section{PRINCIPIE OF OPERATION AND TTEORY}

The electrons coming from the filament in the omegatron are accelerated toward the ionization chamber by the electron bias voltage $V_{B}$ which is 
applied to the filament and electron-beam focus electrode. The electron collector voltage $V_{E}$ causes the electrons to be attracted to the electron collector where they are collected as the emission current $I_{\mathrm{F}}$. As the electrons pass through the ionization chamber they ionize molecules of gas present in the ionization chamber. An alternating electric field $E$ is produced in the ionization chamber by placing an alternating radio frequency ( $R F$ ) voltage $V_{R}$ on the RF electrode. The ions produced by the electron beam interact with the crossed electric and magnetic fields and are accelerated in orbits of increasing size as in a cyclotron. Thus, if the frequency of the alternating electric field is the same as the cyclotron frequency of some particular ion, that ion is collected at the ion collector. The other ions produced get out of phase with the alternating electric field and are not accelerated to the ion collector. A positive trap voltage $V_{T}$ is applied to the sides of the ionization chamber to prevent the plane of the ion orbits from arifting away from the center of the ionization chamber; such drifting would result in the ions not being collected by the ion collector. There are, then, five operating parameters $\left(V_{B}, V_{E}, V_{R}, V_{T}\right.$, and $\left.I_{E}\right)$ which can be varied. The basic difference between the simplified omegatron of this investigation and the original version proposed in reference I by Hipple, Sommer, and Thomas is that the original version employed guard rings around the electric field to insure homogeneity in the electric field and the simplified version does not have the guard rings. McNarry (ref. 12) has shown that the electric field in the simplified omegatron is not homogeneous. The effect of this inhomogeneity is seen in some of the operating parameters.

There are several theoretical treatments of the motion of ions in an omegatron in the literature (refs. 13 and 14). Some useful parameters are given in the appendix.

\section{DESCRIPTION OF APPARATUS}

The vacuum system used for this investigation is shown in figure 3 . The stainless-steel chamber has an internal volume of approximately 20 cubic feet $(0.56 \mathrm{~m})$. The interior of the chamber is 30 inches $(76 \mathrm{~cm})$ in diameter and 42 inches $(107 \mathrm{~cm}$ ) in length (flange to flange). There are nine 5-inch $(12.7 \mathrm{~cm})$ ports on the chamber, two 30-inch-diameter full-opening doors, and the port to which the diffusion pump is attached. All the 5-inch ports are sealed with crushed aluminum "O" rings. The door seals are designed so that either aluminum " $O$ " rings or cooled elastomer " $O$ " rings may be used. A mechanical refrigeration system cools the elastomer "O" rings to $-20^{\circ} \mathrm{C}$ $\left(253^{\circ} \mathrm{K}\right)$, if they are used.

The pumping system is composed of two diffusion pumps in series and a mechanical roughing pump. A 10-inch $(25 \mathrm{~cm}$ ) diffusion pump with a liquid nitrogen cooled baffle is attached to the chamber. The 10-inch diffusion pump is backed by a 2-inch $(5 \mathrm{~cm})$ diffusion pump which is in turn backed by a $15 \mathrm{cu} \mathrm{ft} / \mathrm{min}(0.0071 \mathrm{~m} 3 / \mathrm{sec})$ roughing pump. 
The vacuum chamber and cold trap are covered with custom-fitted heating blankets to bake the system. Removable cap heaters are provided to bake the ports. The vacuum system is normally baked at a temperature of $275^{\circ} \mathrm{C}$ $\left(548^{\circ} \mathrm{K}\right)$. For these tests the pressure was measured by an ionization gage and a magnetron gage. The ultimate pressure in the vacuum chamber as measured by the magnetron gage and corrected to account for the change in sensitivity of the magnetron gage ( $r e f .15$ ) was about $2 \times 10^{-11}$ torr. (All the pressures quoted will be the nitrogen equivalent pressure unless otherwise noted.)

The omegatron tube was mounted on the side of the vacuum system and the magnet was mounted on a track so that it could be rolled away from the omegatron tube in order to bake the tube. Figure 4 is a photograph of the omegatron tube installed on the vacuum system. The magnet is in position for operation of the omegatron. Also shown in figure 4 is the instrumentation used in conjunction with the omegatron tube.

A block diagram of the test apparatus is shown in figure 5 . The bias voltages and the emission current for the omegatron were supplied by a commercial omegatron power supply. The radio-frequency signal was supplied by an oscillator with a sweep-drive mechanism. The frequency was measured by a frequency meter and the data were recorded on an $x-y$ plotter. The ion current from the omegatron was measured by a vibrating-reed electrometer. The connection between the preamplifier of the electrometer and the ion collector pin of the omegatron tube was made with solid coaxial cable utilizing sapphire disk insulators.

\section{PROCEDURE}

Cleaning Omegatron Tube and Magnet Alinement

The omegatron was prepared for the tests by a rigorous cleaning procedure. Since the cleanliness of the tube is essential for operation at very low pressures, the procedure for cleaning the tube will be delineated here. After a pressure of about $2 \times 10^{-10}$ torr had been attained in the vacuum system, the ionization chamber in the omegatron tube was heated white hot by an induction heater to desorb contamination from the metal surfaces and was held at the same temperature for approximately 5 minutes $(300 \mathrm{sec})$. This induction heating was then stopped and the tube was baked with heating tapes at about $400^{\circ} \mathrm{C}$ $\left(673^{\circ} \mathrm{K}\right)$ for about 4 hours to clean the glass walls of the tube. At the end of the bake the tube was again heated by the induction heater for 5 minutes. The electron-beam focus electrode was then biased positive about 500 volts with respect to the filament and the filament was heated until there was a current of 25 to $30 \mu \mathrm{A}$ between the electron-beam focus electrode and the filament. This cleaned the electron focus electrode. The electrical leads for operating the omegatron tube were then attached to the tube and the filament was biased negative about 150 volts with respect to the electron collector. The filament was again heated until there was a current of $20 \mu \mathrm{A}$ between the filament and electron collector. The electron collector was then clean. 
In some cases, however, the cleaning procedure described had to be repeated two or three times to clean the tube properly. If the tube was not cleaned properly, the background current was found to vary with the radio frequency, and anomalous nitrogen and water peaks were observed in the mass scan. The cleanliness of the omegatron also affected the value of trap voltage to give the maximum sensitivity. This effect can be seen in figure 6 which shows the variation of ion current with trap voltage for argon at $8.6 \times 10^{-9}$ torr before and after baking the omegatron tube. Before baking the tube, a trap voltage of 1.0 volt was required to obtain maximum sensitivity. (The sensitivity is defined in equation (13) in the appendix.) After baking, however, the trap voltage for maximum sensitivity was only 0.6 to 0.7 volt. After cleaning the tube several times by baking and induction heating, the value of trap voltage for maximum sensitivity was found to remain constant at 0.6 to 0.7 volt.

After the tube had been cleaned the magnet was rolled into place and alined. The magnet was considered alined when the emission current between the filament and electron collector was equal to the total electron current leaving the filament.

\section{Pressure Measurement}

The pressure in the chamber was measured by a commercial Bayard-Alpert type of gage and a magnetron gage. The Bayard-Alpert gage was used from $2 \times 10^{-10}$ torr to $1 \times 10^{-6}$ torr and the magnetron gage, below $2 \times 10^{-10}$ torr.

The Bayard-Alpert gage was cleaned by baking for about 4 hours at $300^{\circ} \mathrm{C}$ $\left(573^{\circ} \mathrm{K}\right)$, after which a positive potential of 800 volts was placed on the grid and the filament heated until about $125 \mathrm{~mA}$ were drawn from the filament to the grid. Fifteen minutes of this electron bombardment were sufficient to complete the cleaning of the Bayard-Alpert gage. The magnetron gage was cleaned sufficiently by baking at $300^{\circ} \mathrm{C}$ for 4 hours.

\section{Gas Inlet Manifold}

In order to assure that only the spectroscopically pure test gases entered the chamber a special gas inlet manifold was devised. The line from the pressure regulator on the test-gas bottle to the gas inlet valve was evacuated with a roughing pump until the pressure was about 10 microns. The roughing pump was then valved off and the line backfilled with the test gas from the bottle until the pressure was about $5 \mathrm{psig}\left(135 \mathrm{kN} / \mathrm{m}^{2}\right)$. When this procedure was used the amount of air left in the manifold was less than 1 percent of the test gas in the manifold. The leakage of gas into the chamber could be controlled so that the pressure could be controlled even in the 10-1l torr region if desired. 


\section{Test Procedure}

As mentioned previously there are five operating parameters that are of concerm. They are the trap voltage $V_{\mathrm{T}}$, the electron collector voltage $\mathrm{V}_{\mathrm{E}}$, the electron bias voltage $V_{B}$, the $R F$ voltage $V_{R}$, and the emission current $I_{E}$. The variations of magnetic fleld strength will not be considered herein. The variation of all these parameters except the electron bias voltage will be studied. The electron bias voltage was chosen as 70 volts since much of the data in the literature on cracking patterns was obtained with 70 volts for the electron bias voltage. This allowed comparison of the cracking patterns from the omegatron with cracking patterns already documented.

The first series of tests conducted was to determine the dependence of the ion current upon the trap voltage, electron collector voltage, and RF voltage. If the values of trap voltage, electron collector voltage, and RF voltage to give the maximum sensitivity are not dependent upon the gas being analyzed nor upon the pressure of this gas, the omegatron can be used with greater facility as a partial pressure analyzer.

These tests were conducted in the following manner. The vacuum chamber was evacuated and the omegatron tube cleaned as noted. When the pressure in the vacuum chamber was about $2 \times 10-11$ torr, the test-gas inlet valve was opened slowly until the pressure desired was attained, and then the test run was conducted at that particular flow rate and pressure. If the variation of ion current with trap voltage were desired, the trap voltage would be changed manua.1ly and the ion current measured at each setting of the trap voltage. This procedure was repeated at various pressures for four test gases - helium, nitrogen, argon, and carbon dioxide. In a similar manner the variation of ion current with electron collector voltage and $R F$ voltage was determined for the test gases at various pressures.

A second series of tests was conducted to determine the sensitivity of the omegatron for helium, nitrogen, argon, and carbon dioxide. As before, the test=gas inlet valve was opened after a pressure of $2 \times 10^{-11}$ torr had been attained in the vacuum chamber. For these tests, however, at each pressure the frequency of the $R F$ voltage was varied through a range sufficient to cause the various mass-to-charge ratios involved in the test run to become resonant. Since the test-gas peaks corresponded in most cases to very low currents the time constant of the measuring instruments was very long. The frequency had to be changed very slowly to insure that the test-gas peak plotted on the $\mathrm{x}-\mathrm{y}$ plotter was equal to the ion current $I_{C}$. A scan rate of about 2.5 minutes (150 sec) for each peak was necessary to insure that the test-gas peak was equal to the ion current. After the frequency had been varied to determine the peak heights at the first pressure, the test-gas inlet valve was opened further, a higher pressure was obtained, and the frequency again varied to determine the mass-to-charge ratios present. In this manner the sensitivity was determined over a pressure range from about $10^{-10}$ torr to $10^{-6}$ torr.

A scan plotted on the $x-y$ plotter for a test run in which several gases were admitted simultaneously (air, argon, and carbon dioxide) is shown in 
figure 7 and shows how a scan would look for an analysis being made with several gases in the vacuum system. Of course, in the tests to determine the sensitivity of the omegatron for the test gases only one test gas was admitted at a time so that the partial pressure of the test gas would be equal to the total pressure.

In most instances the residual pressure in the chamber before admission of the test gas was about $2 \times 10^{-11}$ torr. If a test gas was admitted to raise the pressure in the chamber to $2 \times 10^{-10}$ torr, the residual gases accounted for about 10 percent of the total pressure and this percentage decreased as the pressure was raised. Thus the residual gases did not contribute significantly to pressures above $2 \times 10^{-10}$ torr.

A third series of tests was conducted to determine whether the variation of ion current with trap voltage, electron collector voltage, and RF voltage was dependent upon the emission current. The tests were conducted by maintaining a constant pressure in the vacuum chamber and varying first the $R F$ voltage, then the electron collector voltage, and finally the trap voltage at various emission currents while monitoring the ion current. These tests were conducted only for argon.

A fourth series of tests was conducted for a separate omegatron tube of the same configuration to determine whether the operating parameters measured for the first tube could be applied to the second one. The sensitivity of the second tube for nitrogen, argon, and carbon dioxide was also measured and compared with that of the first tube.

\section{ACCURACY}

\section{Omegatron Power Supply}

The meters indicating the trap voltage, electron collector voltage, emission current, and electron bias voltage were meters that could be read. directly and were accurate to \pm 2 percent of full scale. Full scale was 3 volts for the trap voltage, 100 volts for the electron collector voltage, $5 \mu \mathrm{A}$ for the emission current, and 150 volts for the electron bias voltage.

\section{RF Oscillator}

The frequency of the RF voltage was measured with a frequency meter which was accurate to \pm 0.001 percent of the indicated frequency. The RF voltage was read from the rms voltmeter on the front of the RF oscillator. Because no accuracy was quoted for this meter, the RF voltage was checked with a separate rms voltmeter having an accuracy of \pm l percent of full scale where full scale was 3 volts rms. The two rms voltmeters agreed. 
Magnet

The magnetic field was measured with a gauss meter with an accuracy of \pm 2 percent so that the magnetic field strength was $3980 \pm 80$ gauss $(0.3980 \pm 0.0080$ tesla)

\section{Electrometer}

The electrometer was calibrated in the current range from 10-9 to 10-12 amperes by using a constant current source that was accurate to $\pm 1 \frac{1}{2}$ percent. The electrometer was accurate to within 15 percent of full scale. The output of the electrometer was plotted on an $x-y$ plotter which had an accuracy of \pm 1 percent of the indicated value.

\section{Pressure Measurement}

Probably the largest inaccuracy in the data comes from the lack of a method of calibrating the pressure gages in the ultrahigh vacuum range below $10^{-9}$ torr. The controller used with the ion gage is accurate within \pm 3 percent of full scale and the gage that was on the chamber was calibrated for nitrogen on an orifice-type calibration station which is accurate to \pm 8 percent, according to the manufacturer. The calibration system is an advanced model of one used by Hayward and Jepsen. (See ref. 16.)

The ionization gage, however, was calibrated only for nitrogen because of the Iimitations of the calibration device. The gage constant for each of the other test gases was also needed in order to determine the sensitivity of the omegatron for each test gas. These gage constants were taken from references 17 and 18. The gage constants taken from the literature for helium, argon, and carbon dioxide are good averages for ionization gage constants but there is no assurance that the particular ionization gage used to measure the pressures in the data reported herein has exactly these gage constants. It is estimated, however, that the agreement was within \pm 20 percent between the gage constant for this ionization gage and the gage constants found in the literature. The gage constant for the magnetron gage was determined by comparing it with the calibrated ionization gage in the pressure range from $5 \times 10^{-7}$ torr to $5 \times 10^{-10}$ torr in which the two gages should agree.

\section{RESULTS AND DISCUSSION}

\section{General}

The five operating parameters that can be varied with the omegatron are the emission current $I_{\mathrm{E}}$, electron bias voltage $V_{\mathrm{B}}$, trap voltage $V_{\mathrm{T}}$, electron collector voltage $V_{E}$, and the RF voltage $V_{R}$. The initial value of emission 
current was chosen as $1 \mu \mathrm{A}$. The electron bias voltage was chosen as 70 volts as noted previously. The initial values of trap voltage, electron collector voltage, and RF voltage must then be determined because two of these three parameters must be fixed while the optimum value of the third is determined. Based on preliminary data, the values of 0.7 volt for the trap voltage, 8 volts for the electron collector voltage, and 1.5 volts rms for RF voltage were chosen for the initial tests.

\section{Variation of Ion Current With Trap Voltage}

The variation of ion current with trap voltage for helium, nitrogen, argon, and carbon dioxide was determined over a pressure range generally from $7 \times 10^{-10}$ torr to $7 \times 10^{-7}$ torr. Figure 8 shows the variation of ion current with trap voltage for helium, nitrogen, argon, and carbon dioxide, respectively. The trend of all the curves is the same, with the maximum ion current at each pressure occurring at a trap voltage of about 0.6 or 0.7 volt for most curves. One apparent anomaly seen for argon is that whereas the pressure increases by a factor of about 10 between test runs the maximum ion current from the middle curve is nearer 20 times that of the lower curve. This occurrence is due to the residual gases other than argon contributing significantly to the total pressure but not to the argon partial pressure. For this test the pressure in the vacuum chamber before the argon was admitted was not low enough. This caused an apparent low sensitivity at the lower pressures because the ionization gage was measuring the total pressure and not the argon partial pressure. At the higher pressures the argon partial pressure was almost the same as the total pressure. This apparent low sensitivity at the lowest pressures also occurs for carbon dioxide.

The trap voltage for maximum sensitivity for the four test gases varied. from 0.4 volt for nitrogen to 1.0 volt for helium at the lowest pressure. The ion current, however, is not a strong function of the trap voltage for any of the test gases over a range of trap voltages from 0.3 volt to 0.7 volt. In fact, except for helium at $5.9 \times 10^{-9}$ torr, the trap voltage can be varied from 0.3 volt to 0.7 volt for any of the test gases and for any of the test pressures and the sensitivity will be reduced by, at most, about 10 percent of the maximum sensitivity. Based on the data in figure 8, the value recommended for the trap voltage is 0.7 volt. Although no single value of the trap voltage will give the maximum sensitivity for all the test gases, the recommended trap voltage of 0.7 volt will give within about 10 percent of the maximum sensitivity. The value of 0.7 volt for the trap voltage was used for the rest of the test series.

\section{Variation of Ion Current With Electron Collector Voltage}

The variation of the ion current with electron collector voltage for helium, nitrogen, argon, and carbon dioxide was determined for pressures genera11y from $7 \times 10^{-10}$ torr to $7 \times 10^{-7}$ torr. This variation is shown for helium, nitrogen, argon, and carbon dioxide in figure 9 . As this figure shows, 
the trends are all about the same, with the maximum ion current at each pressure at about 8 volts.

These figures also show that the ion current is not a strong function of the electron collector voltage for any of the test gases in the range from 6 to 12 volts. With the exception of carbon dioxide at $8.3 \times 10^{-10}$ torr, variations of the electron collector voltage in the range from 6 volts to 12 volts caused a reduction in the ion current of, at most, 10 percent from the maximum value of the ion current. The recommended value of the electron collector voitage is 8 volts and this value was used in the remainder of the test runs.

\section{Variation of Ion Current With RF Voltage}

In the preceding sections, the variation of ion current with trap voltage and electron collector voltage has been established. Now the variation of ion current with RF voltage must be considered. The variation of ion current with RF voltage for helium, nitrogen, argon, and carbon dioxide is shown in figure 10. The trend of all the curves is about the same with the maximum ion current at each pressure at about 1.5 to 2.0 volts rms. The curves for helium do not show a peak because the data were not taken at high enough RF voltages. The ion current is not a strong function of the RF voltage from about 1.5 to 2.5 volts rms. For reasons which will be explained subsequently in the section entitled "Sensitivity" the RF voltage chosen was 1.5 volts rms.

\section{Variation of Ion Current With RF Voltage, Electron Collector Voltage, and Trap Voltage at Various Emission Currents}

The recormended values of trap voltage, electron collector voltage, and RF voltage for helium, nitrogen, argon, and carbon dioxide have been established. These values were established at an emission current of $1 \mu \mathrm{A}$. If the omegatron could be operated at higher emission currents, the ion current might be higher and allow a lower limit to the detectable pressure level. The next test series was conducted to determine the variation of the ion current with RF voltage, trap voltage, and electron collector voltage at various emission currents for argon while the pressure was held constant.

The variation of ion current with $R F$ voltage for argon at emission currents from $0.25 \mu \mathrm{A}$ to $5 \mu \mathrm{A}$ is shown in figure 11. Each curve represents the data taken at one emission current. For emission currents from $0.25 \mu \mathrm{A}$ to $1 \mu \mathrm{A}$ the $R F$ voltage for maximum sensitivity is almost constant at 2 volts rms. For emission currents greater than $2 \mu \mathrm{A}$ the value of $\mathrm{RF}$ voltage for maximum sensitivity increases as the emission current increases.

Figure $I I$ also shows that for a constant value of the $R F$ voltage the ion current is not directly proportional to the emission current. If, for example, at an $\mathrm{RF}$ voltage of 1.5 volts rms the emission current is increased from $2 \mu \mathrm{A}$ to $3 \mu \mathrm{A}$, the ion current is actually decreased instead of increased. Increasing the emission current, therefore, will not necessarily increase the 
ion current and can even decrease it. This occurrence in the simple omegatron configuration has also been noted by Edwards (ref. 19), who suggested that it may be caused by a space charge in the ionization chamber of the omegatron tube. This space charge, Edwards suggests, is caused by the electron beam and the nonresonant ions around the electron beam. This space-charge effect has also been investigated and reported in reference 13 by Schuchhardt for another omegatron configuration. Schuchhardt noted that for pressures below

$5 \times 10^{-7}$ torr the effect of the electron beam predominates the effect of the positive nonresonant ions. This occurrence is consistent with figure 10 which shows almost no pressure effect on the shape of the curves. From the data presented in figure 11 it appears that emission currents up to $2 \mu \mathrm{A}$ could be used at an RF voltage of 1.5 volts rms. Increasing the emission current above $2 \mu \mathrm{A}$ could cause the ion current to decrease if the RF voltage were 1.5 volts rms.

The variation of ion current with trap voltage for argon at emission currents from $0.25 \mu \mathrm{A}$ to $5 \mu \mathrm{A}$ is shown in figure 12 at a pressure of

$8.0 \times 10^{-9}$ torr. The $\mathrm{RF}$ voltage at each emission current in figure 12 is determined from figure 11 as the $R F^{\prime}$ voltage to give the maximum sensitivity at each of the emission currents. The trap voltage for maximum sensitivity ranges from 0.4 to 0.7 volt as the emission current is changed. Even when the RF voltage is adjusted, the maximum ion current is not proportional to the emission current for emission currents greater than $2 \mu \mathrm{A}$. This fact is further evidence that the ion current is not directly proportional to the emission current for emission currents greater than $2 \mu \mathrm{A}$. The value of the trap voltage for maximum sensitivity is, however, almost independent of the emission current in the range of emission currents from $0.25 \mu \mathrm{A}$ to $5 \mu \mathrm{A}$.

The variation of ion current with electron collector voltage for argon at emission currents from $0.25 \mu \mathrm{A}$ to $1 \mu \mathrm{A}$ is shown in figure 13 . The value of electron collector voltage for maximum sensitivity varies slightly with the emission current at a pressure of $8.3 \times 10^{-9}$ torr. At $0.25 \mu \mathrm{A}, 0.5 \mu \mathrm{A}$, and $0.75 \mu \mathrm{A}$ the electron collector voltage for maximum sensitivity is 6 volts. At $1 \mu \mathrm{A}$ the electron collector voltage for maximum sensitivity is 8 volts. Again the ion current is roughly proportional to the emission current in this range of emission currents.

\section{Sensitivity}

The sensitivity of the omegatron was found to depend in varying degrees upon the RF voltage, trap voltage, and electron collector voltage as well as upon the parameters indicated in equation (13) in the appendix. Therefore the sensitivity will be defined for constant values of RF voltage, trap voltage, and electron collector voltage. The recommended values of trap voltage and electron collector voltage were chosen to maximize the sensitivity for the test gases and the pressure range considered. The $R F$ voltage for maximum sensitivity varied from about 1.5 volts rms to 2 volts rms from figure 10. The recommended operating $R F$ voltage was chosen as 1.5 volts rms. One reason for this choice comes from consideration of equation (12) in the appendix, which shows that the path length of the resonant ion $\lambda$ is inversely proportional to the electric field strength E. (The electric field strength is equal to the RF voltage divided by $2 \mathrm{~cm}$.$) The ion current in the omegatron for any given pressure and$ 
emission current is a function of the ion path length. If the ion path length is long the chance that resonant ions will be removed from their cyclic orbits by random collision with other ions is greater than if the ion path length is short. Thus, if the electric field strength is increased the ion path length will be decreased and, correspondingly, the sensitivity will be increased. Equation (12) also shows, however, that the resolution is inversely proportional to the electric field strength. Since the resolution should be high the electric field strength should be low, and since the sensitivity should be high the electric field strength should be high. Obviously the electric field strength (or RF voltage) must be a compromise between sensitivity and resolution. The reduction of the sensitivity caused by the change in the resonant-ion path length cannot account for the magnitude of the reduction in sensitivity as the RF voltage is reduced, shown in figure 10. This reduction is no doubt caused by the space-charge effect discussed. For partial-pressure analysis in ultrahigh vacuum the sensitivity must be high and, for this reason, the RF voltage was chosen more for maximum sensitivity than for maximum resolution. An RF voltage of 1.5 volts rms was chosen because at this voltage the sensitivity is reduced by only 10 percent of its maximum value.

The sensitivity of the omegatron for helium, nitrogen, argon, and carbon dioxide is determined from the data presented in figures 14, 15, 16, and 17, respectively. In each figure the ion current from the test gas is plotted as a function of the pressure in the vacuum system for an emission current of $1 \mu \mathrm{A}$. The line through the data was computed by the method of least squares. The points in the figure that fall well below the line are from the so-called "cracking pattern" and are the heights of the peaks other than the parent peak in each test run that can be attributed to the test gas. If the sensitivity were independent of pressure the ion current would be directly proportional to pressure and the slope of the line in figures 14, 15, 16, and 17 would be 1. Actually, these slopes are 1.02, 1.014, 1.034, and 0.924, respectively. Since the slope of these lines is not 1 the sensitivity appears to be dependent upon the pressure.

That there is only a slight sensitivity dependence upon the pressure for helium, nitrogen, and argon is seen from the fact that the slope of the ioncurrent-pressure line in figures 14, 15, and 16 is only slightly greater than 1. There are reasons to expect the slope of this line to be slightly greater than 1 . At low pressures the residual gases in the vacuum system constitute a larger percentage of the pressure than at higher pressures so that at low pressures the partial pressure of the test gas is not equal to the total pressure. This effect of the residual gases would cause an apparent low sensitivity at low pressures and therefore the slope of the line would be greater than 1 .

The slope of the ion-current-pressure line for carbon dioxide is shown in figure 17 and is 0.924 . This apparent increase in the sensitivity at low pressures is an anomaly, and a reason for it is lacking.

The pressures in figures 14 to 17 are equivalent nitrogen pressures. These pressures must be corrected to account for the change in ionization gage sensitivity for each test gas. The true pressure can then be used to calculate the sensitivities from equation (13) in the appendix. By using the values of 
the ionization gage sensitivity for helium and argon from reference 17 and the value for carbon dioxide from reference 18, the true pressures were determined for the test gases for an equivalent nitrogen pressure of $10^{-9}$ torr. By using the values of the ion current at $10^{-9}$ torr from figures 14 to 17 and the true pressures, the sensitivity of the omegatron for the test gases was calculated at an equivalent nitrogen pressure of 10-9 torr. These omegatron sensitivites and the ionization gage sensitivities are shown in table $I$. The sensitivity of the omegatron is slightly higher than the sensitivity of the ionization gage.

Resolution

As already noted, the resolution of the omegatron (eq. (8)) could be improved by reducing the $R F$ voltage. For an $R F$ voltage of 1.5 volts rms the theoretical resolution was computed from equation (8) in the appendix for various gases. The resolution could also be measured because $2 \epsilon^{\prime}$ in equation (8) is the width of the base of the resonant-ion peak. The theoretical and measured resolutions are listed in table II for various mass-to-charge ratios. The theoretical resolution is seen to be about 1.5 times the actual resolution. This relation between values can be accounted for by the fact that the average electric field inside the ionization chamber was used to calculate the theoretical resolution, whereas the actual electric field in the vicinity of the electron beam is less than the average electric field. 1

Comparison of Theoretical and Measured Cyclotron Frequencies

The theoretical and measured values of the cyclotron frequencies are listed in table II. The measured value of the cyclotron frequency was within 1 percent of the theoretical value.

\section{Comparison of the Operating Parameters for Two Omegatron Tubes}

Unless the data taken for this particular omegatron tube can be used for other like tubes, each omegatron tube must be studied to determine its operating parameters. Data taken from two tubes are presented in figures 18, 19, 20, and 21. Tube 1 is the tube already discussed and tube 2 is another one with the same physical configuration from the same manufacturer. The variation of ion current with trap voltage, electron collector voltage, and RF voltage for nitrogen for the two tubes is shown in figure 18. In the plot for trap voltage, the ion current from tube 1 begins to decrease at about 0.5 volt whereas the ion current from tube 2 varies only slightly from 0 to 2 volts. The shape of the ion-current-electron-collector curves for the two tubes is the same except for the range from 0 to 2 volts. The shape of the ion-current-RF-voltage curves

IIt will be noticed that the theoretical resolution presented here differs from that presented in table II of reference 10. The resolution in reference 10 was calculated from equation (3) in reference 4, in which there appears to be an error in that the constant should be 48 rather than 96 . The theoretical resolution presented herein is calculated from equation (8) of this paper. 
for the two tubes shows the same trend for both tubes. It is important to note that, even though the data from the two tubes are different in some of the ranges of the parameters, the range of voltages in which the maximum sensitivity is reduced by about 10 percent is such that the already chosen values - trap voltage of 0.7 volt, electron collector voltage of 8 volts, and RF voltage of 1.5 volts rms - still give within about 10 percent of the maximum sensitivity for both tubes.

The operating parameters have been shown to be similar for nitrogen for two separate tubes and now the sensitivities of the two tubes are compared. Figure 19 shows the variation of ion current with pressure for the two omegatron tubes for nitrogen. (The Iines shown in figures 19, 20, and 21 are repeated from figures 15,16 , and 17, respectively.) The figure shows the sensitivity to be almost, if not exactly, the same for each tube. Figure 20 shows the variation of ion current with pressure for argon. In this figure, a slight difference in the sensitivity is shown by the data from tube I being slightly above the line and the data from tube 2 being slightly below the line. Again, however, the sensitivities are almost the same. The variation of ion current with pressure for two tubes for carbon dioxide is shown in figure 21 . The sensitivity of each tube for carbon dioxide is also about the same.

There is, then, very good agreement in the variation of ion current with trap voltage, electron collector voltage, and $R F$ voltage between the two omegatron tubes for the particular test comparisons, and the sensitivity of each tube for nitrogen, argon, and carbon dioxide is essentially the same.

\section{CONCLUSIONS}

This investigation was made in order to determine whether the value of the operating parameters of the omegatron that gave a high sensitivity at pressures around 10-7 torr also gave a high sensitivity at pressures around 10-10 torr. All data taken show that the optimum operating parameters are not a function of the pressure in this pressure range or of the gas for helium, nitrogen, argon, and carbon dioxide. There is a range of trap voltage and electron collector voltage in which the ion current is not a strong function of these parameters. Some further conclusions are listed as follows:

1. The trap voltage can be set anywhere in the range from 0.3 volt to 0.7 volt, with the exception noted, and the sensitivity of the omegatron will be reduced by, at most, about 10 percent of the maximum sensitivity. This range is independent of pressure from $7 \times 10^{-10}$ torr to $7 \times 10^{-7}$ torr, of gas for hellum, nitrogen, argon, and carbon dioxide, and essentially independent of emission current from $0.25 \mu \mathrm{A}$ to $5 \mu \mathrm{A}$. The recommended value of the trap voltage is 0.7 volt.

2. The electron collector voltage can be set anywhere in the range from 6 volts to 12 volts, with the exception noted, and the sensitivity will be reduced by, at most, about 10 percent of the maximum sensitivity. This range is independent of pressure from $7 \times 10^{-10}$ torr to $7 \times 10^{-7}$ torr, of gas for helium, 
nitrogen, argon, and carbon dioxide, and of emission current from $0.25 \mu \mathrm{A}$ to $5 \mathrm{\mu A}$. The recommended value of the electron collector voltage is 8 volts.

3. The RF voltage of 1.5 volts rms gives within about 10 percent of the maximum sensitivity for pressures from $7 \times 10^{-10}$ torr to $7 \times 10^{-7}$ torr, for the gases helium, nitrogen, argon, and carbon dioxide, and for emission currents from $0.25 \mu \mathrm{A}$ to $2 \mu \mathrm{A}$. For emission currents greater than $2 \mu \mathrm{A}$ the RF voltage for maximum sensitivity increases with increasing emission current.

4. The ion current is essentially directly proportional to the emission current for emission currents from $0.25 \mu \mathrm{A}$ to $2 \mu \mathrm{A}$ but is not directly proportional to the emission current for emission currents greater than $2 \mu A$.

5. The sensitivity of the omegatron is only slightly dependent on the pressure. The sensitivity of the omegatron at 10-9 torr is 1.2 torr-1 for helium, 7.5 torr $^{-1}$ for nitrogen, 11.3 torr $^{-1}$ for argon, and 17.0 torr $^{-1}$ for carbon dioxide.

6. The theoretical resolution of the simplified omegatron is about 1.5 times the actual resolution.

7. The operating parameters and sensitivity for two separate omegatron tubes were essentially the same.

Langley Research Center,

National Aeronautics and Space Administration,

Langley Station, Hampton, Va., July 29, 1965. 


\section{APPEIDIX \\ RELATION BETWEEN SOME OF THE PARAMETERS \\ OF THE OMEGATRON}

There are several theoretical treatments of the motion of lons in an omegatron in the Iiterature (refs. 13 and 14). Some useful parameters are discussed in this appendix.

An expression for the radius of the orbit of an ion in the omegatron is

$$
r=\frac{E}{B \epsilon} \sin \frac{\epsilon t}{2}
$$

where $E$ is the strength of the alternating electric field, $B$ is the magnetic flux density, $t$ is the time measured after the ion is formed, and

$$
\epsilon=\left|\omega-\omega_{c}\right|
$$

in radians per second. In equation (2) $\omega$ is the angular frequency of the RF electric field and $\omega_{c}$ is the cyclotron angular frequency of an ion with a particular $\mathrm{e} / \mathrm{m}$ value given by

$$
\omega_{c}=\frac{e B}{m}
$$

where $e$ is the electron charge in emu and $m$ is the mass of the ion in grams.

If the frequency of the RF electric field approaches the cyclotron frequency of a particular ion - in other words, as $\epsilon \rightarrow 0$ - then that particular ion approaches its resonant condition; and, if $\epsilon \rightarrow 0$ in equation ( 1 ), the radius of the resonant-ion orbit is given by

$$
r_{t}=\frac{E t}{2 B}
$$

where $r_{t}$ is the radius of the resonant-ion orbit at time $t$. Thus, the radius of the resonant-ion orbit increases uniformly with time and the path of the resonant ion is an Archimedes' spiral.

There are nonresonant ions present in the omegatron with cyclotron frequencies very close to the RF frequency and some of these ions will also be collected. A range of cyclotron frequencies, therefore, will be near enough to the radio frequency for ions with cyclotron frequencies that fall within this 


\section{APPENDIX}

range to be collected also. This range of frequencies can be evaluated by considering equation ( 1 ). Based on equation ( 1 ), if the ion collector is located a distance $r_{0}$ from the electron beam, the ion with a cyclotron frequency $\omega_{c}$ will never reach the collector if

$$
r_{0}>\frac{E}{B \epsilon}
$$

There is, then, a critical value of $\epsilon$ for which the ions will reach the collector. This critical value $\epsilon^{\mathrm{r}}$ is given by

$$
\epsilon^{\prime}=\frac{E}{r_{0}^{B}}
$$

Thus an ion with a cyclotron frequency $\omega_{c}$ will be collected if

$$
\omega-\omega_{c} \leqq \frac{E}{r_{0} B}
$$

The resolution of the omegatron is defined as

$$
R=\frac{\omega_{c}}{2 \epsilon^{\prime}}=\frac{\operatorname{er}_{0} B^{2}}{2 E m}
$$

In practical units

$$
R=\frac{\left(4.8 \times 10^{-5}\right) r_{O} B^{2}}{E_{O} \mathrm{M}}
$$

where $r_{0}$ is in centimeters, $B$ is in gauss, $E_{O}$ is in volts per centimeter, and $M$ is in atomic mass units. The resolution can be measured experimentally because the $2 \epsilon^{\prime}$ term in equation (8) is the width of the resonant-ion peak measured at the base of the peak.

The length of an Archimedes' spiral is approximately equal to the number of revolutions times the average orbit circumference. The path length of the resonant ion as it spirals to the collector is thus given by

$$
\lambda=\mathrm{n} \pi \mathrm{r}_{0}
$$

where $n$ is the number of turns made by the resonant ion prior to being collected. Based on equation (3) 


$$
\omega_{c}=\frac{e B}{m}=2 \pi f_{c}=\frac{2 \pi n}{t_{O}}
$$

and, therefore, from equation (10) and equation (4)

$$
\pi n=\frac{e B t_{O}}{2 m}=\frac{e^{2} r_{O}}{m E}
$$

where $t_{0}$ is the time it takes the resonant ion to reach a radius $r_{O}$.

The resonant-ion path length is therefore given by

$$
\lambda=\frac{e B^{2} r_{0}{ }^{2}}{m E}=2 r_{0} R
$$

remembering that $R$ is the resolution.

The sensitivity of the omegatron is defined by

$$
s=\frac{I_{C}}{I_{E} P}
$$

where $I_{C}$ is the ion current, $I_{E}$ is the emission current, and $P$ is the pressure existing in the omegatron. The ion collector current in the omegatron for any given pressure and emission current is influenced by the ion path length given in equation (12). Any increase in the ion path length wilI increase the chance that ions will be removed from their cyclic orbit and thus not be collected. Thus for maximum sensitivity the ion path length should be as short as possible. But from equation (12) decreasing the ion path length will also decrease the resolution and therefore there must be a compromise between sensitivity and resolution to determine the values of $r_{0}, B$, and $E$ in equation (12). 
REF'HRETNCES

1. Hipple, J. A.; Sommer, H.; and Thomas, H. A.: A Precise Method of Determining the Faraday by Magnetic Resonance. Phys. Rev. (Letters to Ed.), ser. 2, vol. 76, no. 12, Dec. 15, 1949, pp. 1877-1878.

2. Sommer, H.; Thomas, H. A.; and Hipple, J. A.: The Measurement of e/M by Cyclotron Resonance. Phys. Rev., ser. 2, vol. 82, no. 5, June 1, 1951, pp. 697-702.

3. Alpert, D.; and Buritz, R. S.: UItra-High Vacuum. II. Iimiting Factors on the Attainment of Very Low Pressures. J. Appl. Phys., vol. 25, no. 2, Feb. 1954, pp. 202-209.

4. Zdanuk, E. J.; Bierig, R.; Rubin, L. G.; and Wolsky, S. P.: An Omegatron Spectrometer, Its Characteristics and Application. Vacuum, vol. 10, no. 5, 1960, pp. 382-389.

5. Stark, D. S.: Measurements on the Properties of a Simple Omegatron. Vacuum, vol. 9, nos. 5/6, 1959/60, pp. 288-294.

6. Baker, Franklin A.; and Giorgi, Tiziano A.: The Applicability of the Omegatron to Continuous Analysis of Residual Gases. Vacuum, vol. 10, nos. 1/2, 1960, pp. 58-63.

7. Lawson, R. W.: An Omegatron for Quantitative Partial Pressure Measurement Below 1 Microtorr. J. Sci. Instr., vol. 39, no. 6, June 1962, pp. 281-286.

8. Dïmler, S.: Untersuchungen ïber die Verwendbarkeit des Omegatrons zur quantitativen Partialdruckanalyse im Hochvakuum. Vakuum-Technik, 1961. Pt. I, vol. 10, no. 5, pp. 131-138.

Pt. II, vol. 10, no. 6, pp. 184-190.

9. Reich, G.; and Nöller, H. G.: Eine Gegenüberstellung der Partialdruckmessgeräte Topatron und Omegatron. 1961 Transactions of the Eighth Vacuum Symposium and Second International Congress, Vol. 1, Luther E. Preuss, ed., The Macmillan Co., 1962, pp. 560-566.

10. Bradford, James M., Jr.: The Omegatron in Ultra High Vacuum Partial Pressure Analysis. M. A. Thesis, The College of William and Mary in Virginia, 1964.

11. Mechtly, E. A.: The International System of Units - Physical Constants and Conversion Factors. NASA SP-7012, 1964.

12. McNarry, L. R.: Development of a Miniature Mass Spectrometer of the Omegatron Type. NRC No. 4259 (ERA-311), Natl. Res. Council Can. (Ottawa), Dec. 1960. (Available from ASTIA as AD No. 131657.) 
13. Schuchhardt, G.: Ion Movements in an Omegatron. Vacuum, vol. 10, no. 5, 1960, pp. 373-3.5.

14. Berry, Clifford E.: Ion Trajectories in the Omegatron. J. Appl. Phys., vol. 25, no. 1, Jan. 1954, pp. 28-31.

15. Torney, Franklin L., Jr.; and Feakes, Frank: Pressure Measurements Below 10-10 Torr with Bayard-Alpert and Magnetron Gauges. Rev. Sci. Instr., vol. 34, no. 9, Sept. 1963, pp. 1041-1043.

16. Hayward, W. H.; and Jepsen, R. I.: A Simple High Vacuum Gauge Calibration System. 1962 Transactions of the Ninth National Vacuum Symposium of the American Vacuum Society, George H. Bancroft, ed., The Macmillan Co., c.1962, pp. 459-462.

17. Dushman, S.; and Young, A. H.: Calibration of Ionization Gauge for Different Gases. Phys. Rev. (Letters to Ed.), ser. 2, vol. 68, nos. 11 \& 12, Dec. 1 \& 15, 1945, p. 278.

18. Wagener, S.; and Johnson, C. B.: Calibration of Ionization Gauges for Various Gases at Low Pressures. J. Sci. Instr., vol. 28, 1951, p. 278.

19. Edwards, A. G.: Some Properties of a Simple Omegatron-Type Mass Spectrometer. Brit. J. Appl. Phys., vol. 6, no. 2, Feb. 1955, pp. 44-48. 
TABLE I. - COMPARISON OF OMEGATRON AND

IONIZATION GAGE SENSITIVITIES

\begin{tabular}{|l|c|c|}
\hline Gas & $\begin{array}{c}\text { Ionization gage } \\
\text { sensitivity, } \\
\text { torr-1 }\end{array}$ & $\begin{array}{c}\text { Omegatron } \\
\text { sensitivity, } \\
\text { torr-1 }\end{array}$ \\
\hline Helium & 1.0 & 1.2 \\
Nitrogen & 6.6 & 7.5 \\
Argon & 7.9 & 11.3 \\
Carbon dioxide & 9.0 & 17.0 \\
\hline
\end{tabular}

TABLE II. - CYCLOTRON FREQUENCY AND RESOLUTION FOR VARIOUS VALUES OF $\mathrm{m} / \mathrm{e}$

\begin{tabular}{|c|c|c|c|c|}
\hline \multirow{2}{*}{$\mathrm{m} / \mathrm{e}$} & \multicolumn{2}{|c|}{$\begin{array}{c}\text { Cyclotron } \\
\text { kcps }\end{array}$} & $\begin{array}{c}\text { frequency, } \\
(\mathrm{kHz})\end{array}$ & \multicolumn{2}{|c|}{ Resolution } \\
\cline { 2 - 5 } & Theoretical & Measured & Theoretical & Measured \\
\hline 4 & 1527 & 1542 & 138 & 86 \\
16 & 382 & 385 & 35 & 18 \\
20 & 305 & 308 & 28 & 21 \\
28 & 218 & 219 & 20 & 15 \\
32 & 191 & 191.5 & 17 & 11 \\
40 & 153 & 153 & 14 & 10 \\
44 & 139 & 139 & 13 & 9 \\
\hline
\end{tabular}


Direction of

magnetic field



Figure 1.- Physical arrangement of electrodes inside omegatron tube. 




Figure 2.- Omegatron tube. 


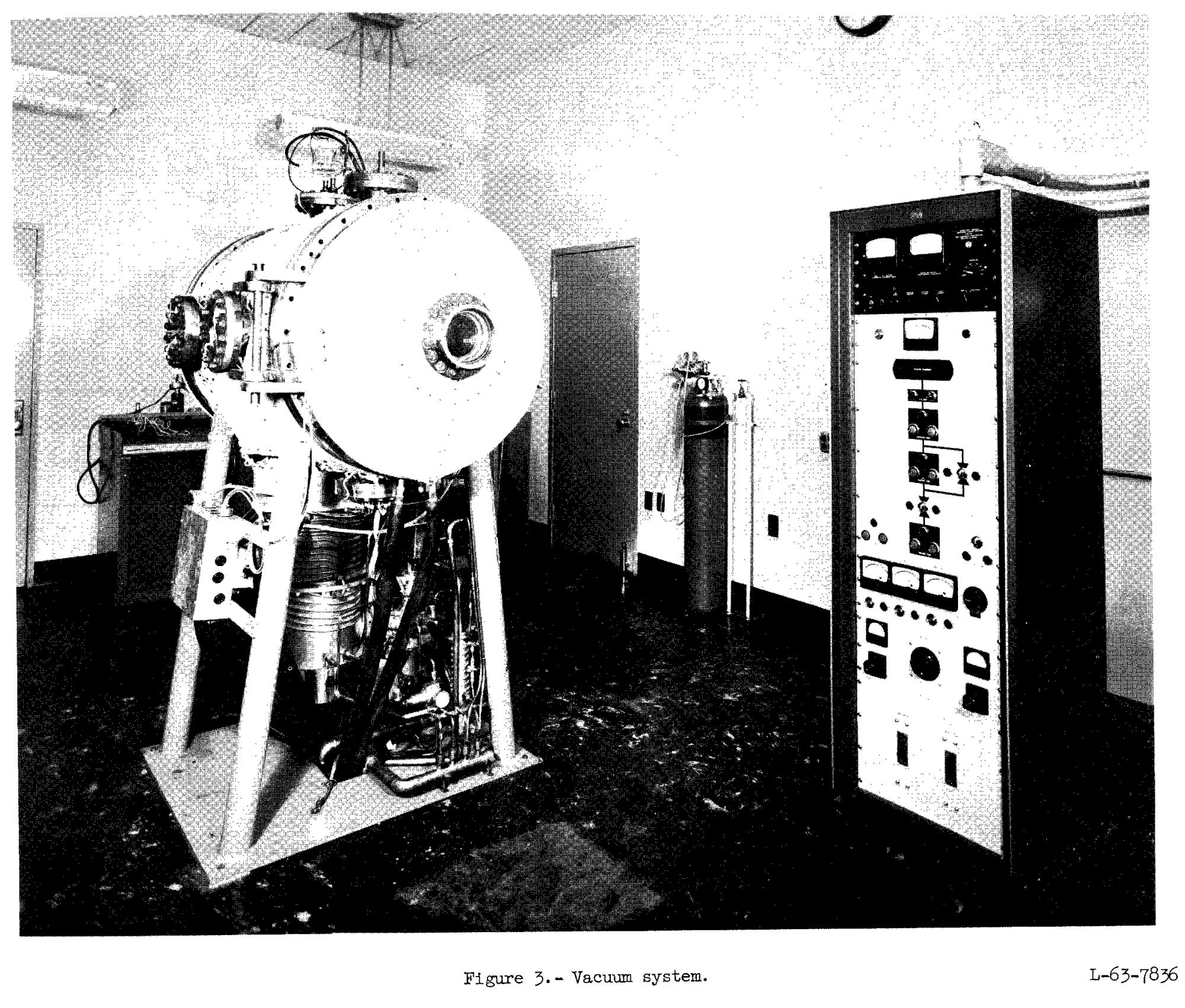






L-64-3144.1

Figure 4.- Vacuura chamber with omegatron attached and instrumentation for operation of omegatron. 


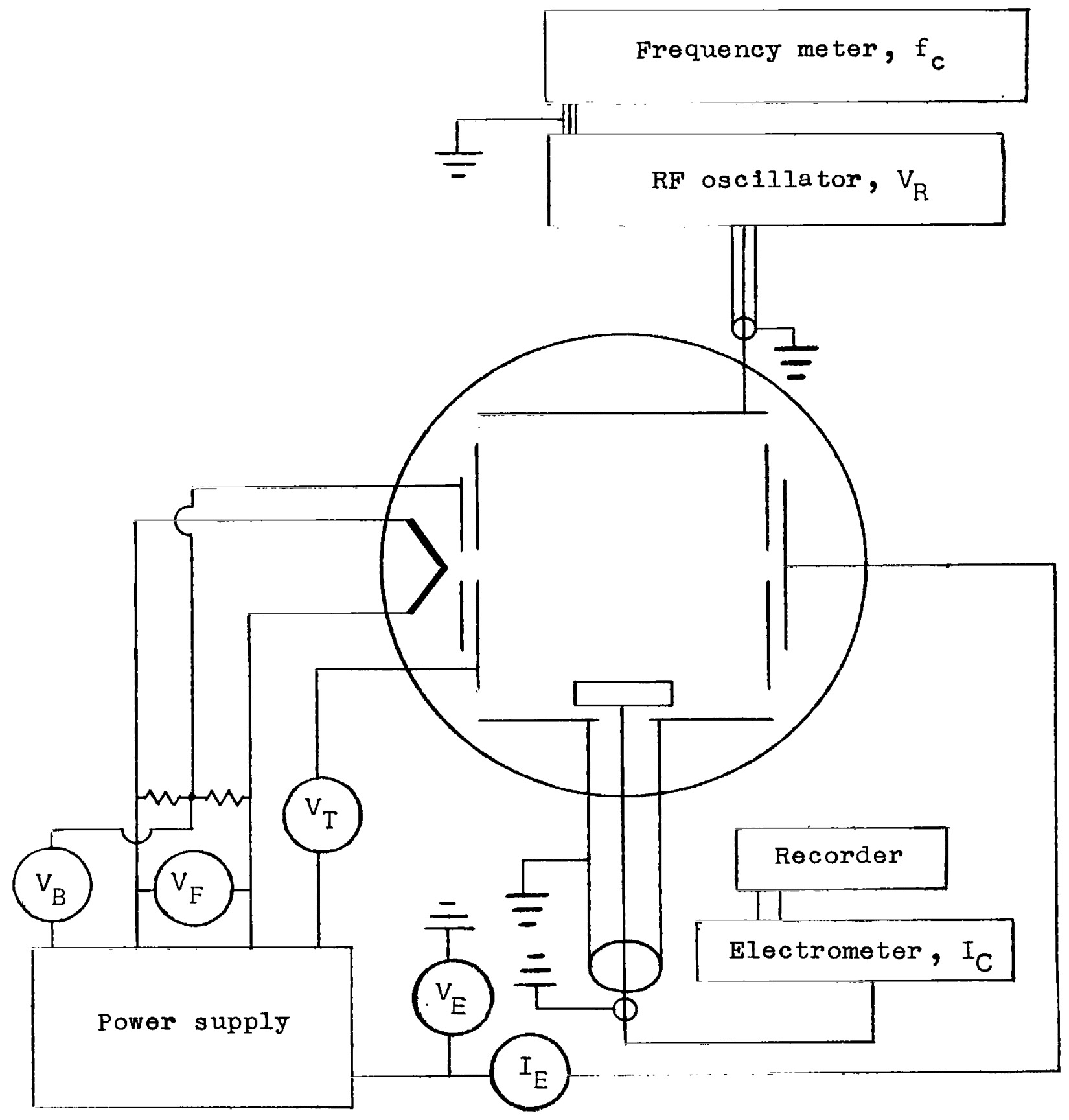

Figure 5.- Block dlagram for omegatron test apparatus. 


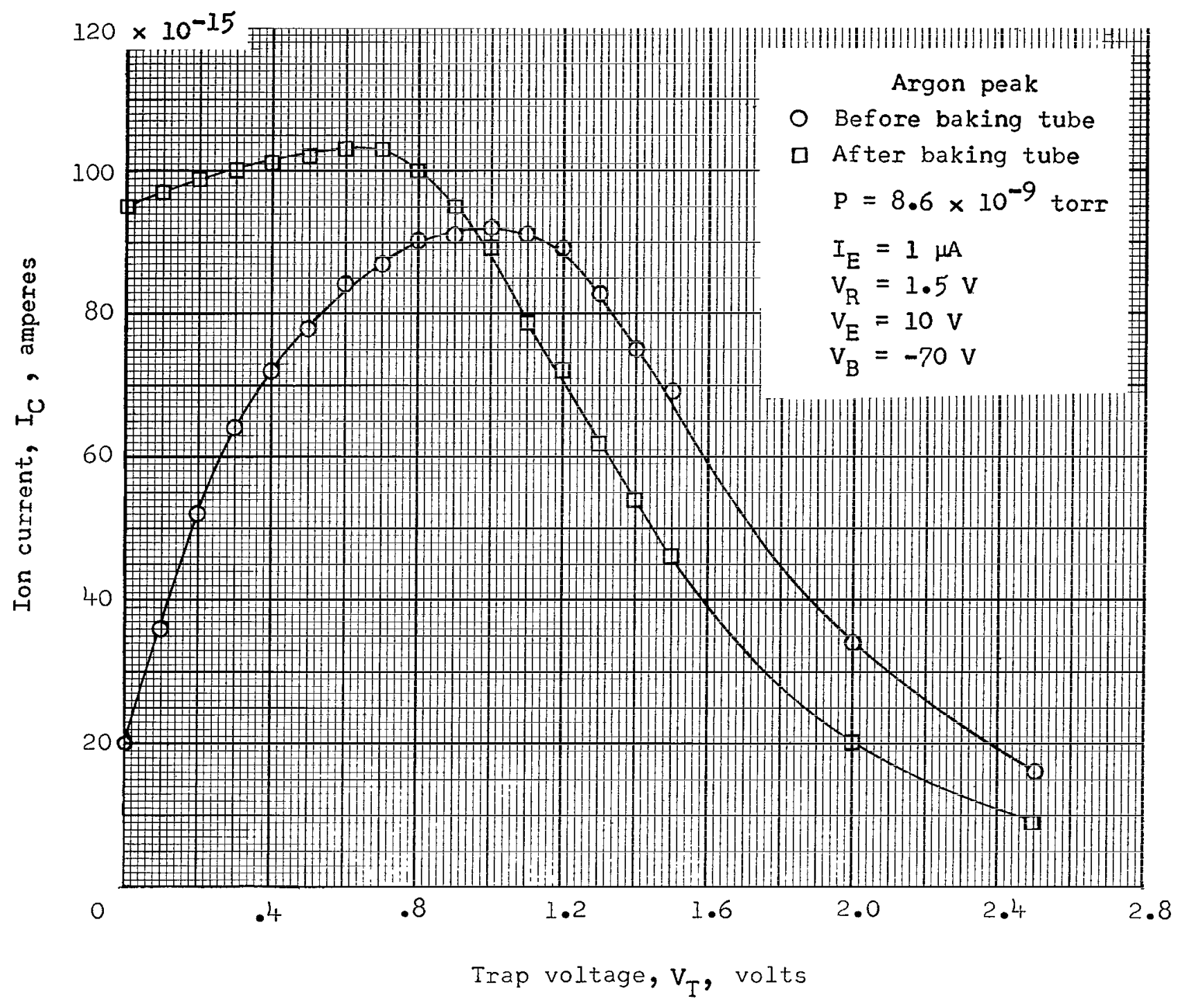

Figure 6.- Variation of ion current with trap voltage for argon before and after baking omegatron tube. 


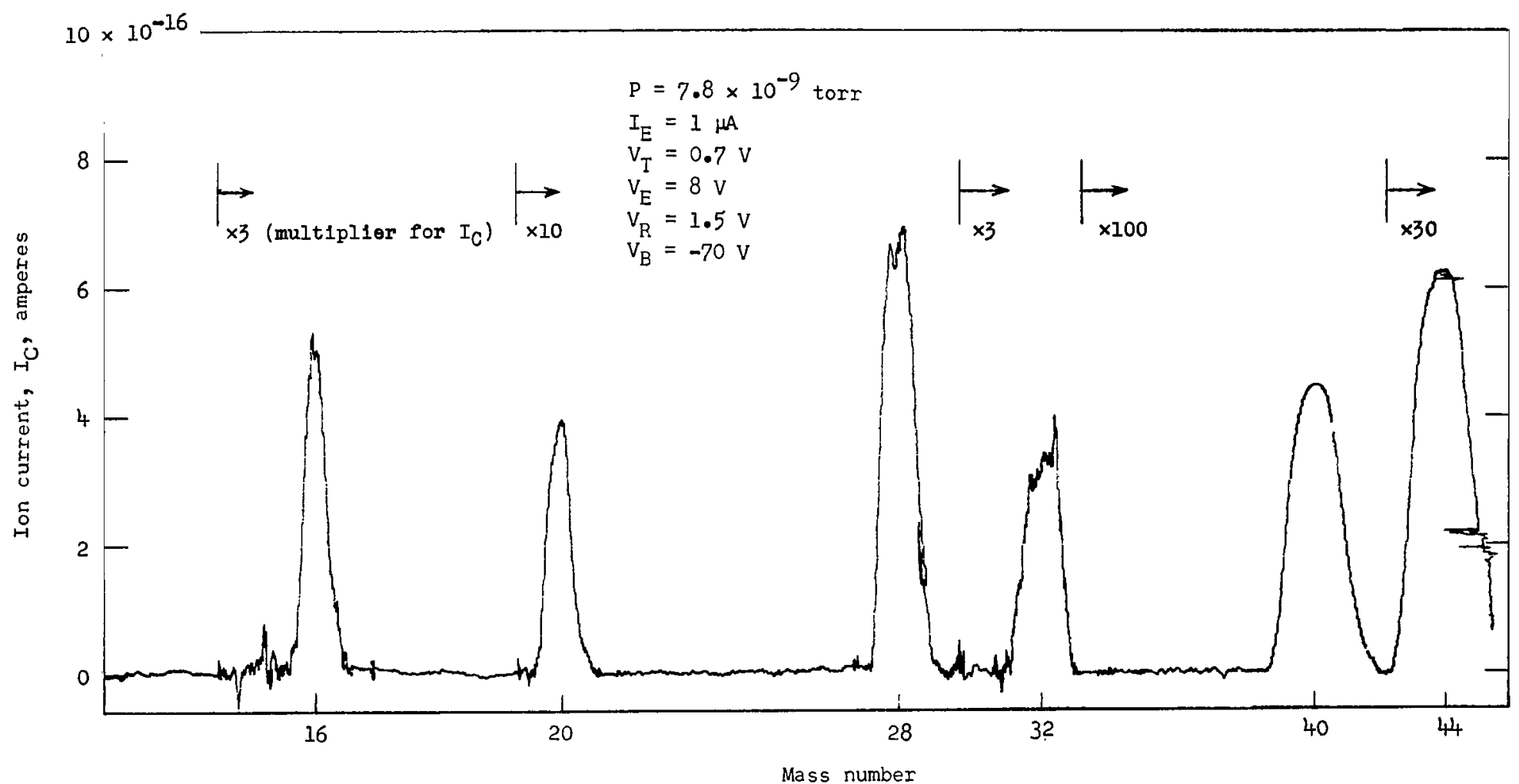

Figure 7.- Mass scan for test in which air, argon, and carbon dioxide were admitted simultaneously. 



Figure 8.- Variation of ion current with trap voltage at various pressures. 

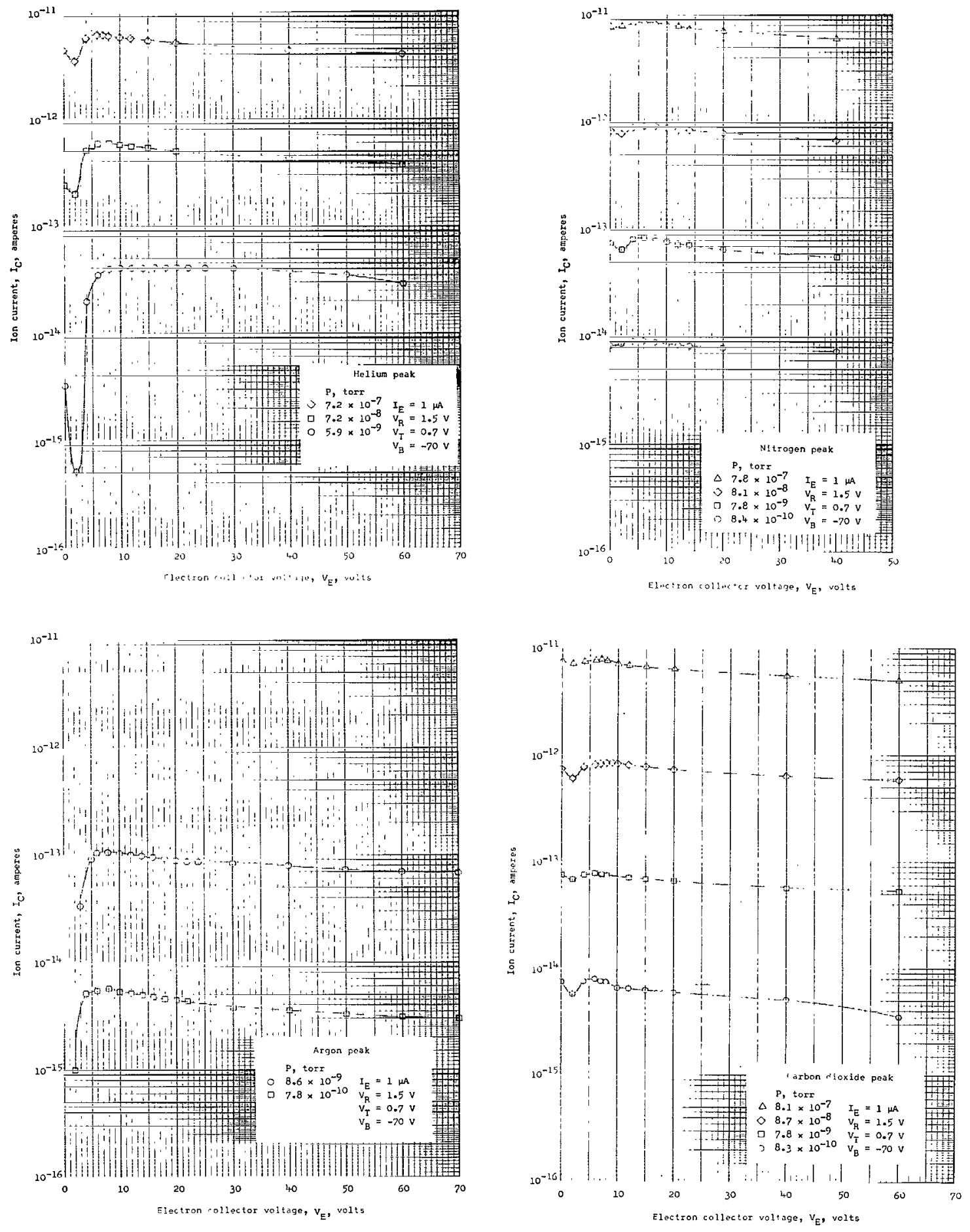

Figure 9.- Variation of ion current with electron collector voltage at various pressures. 

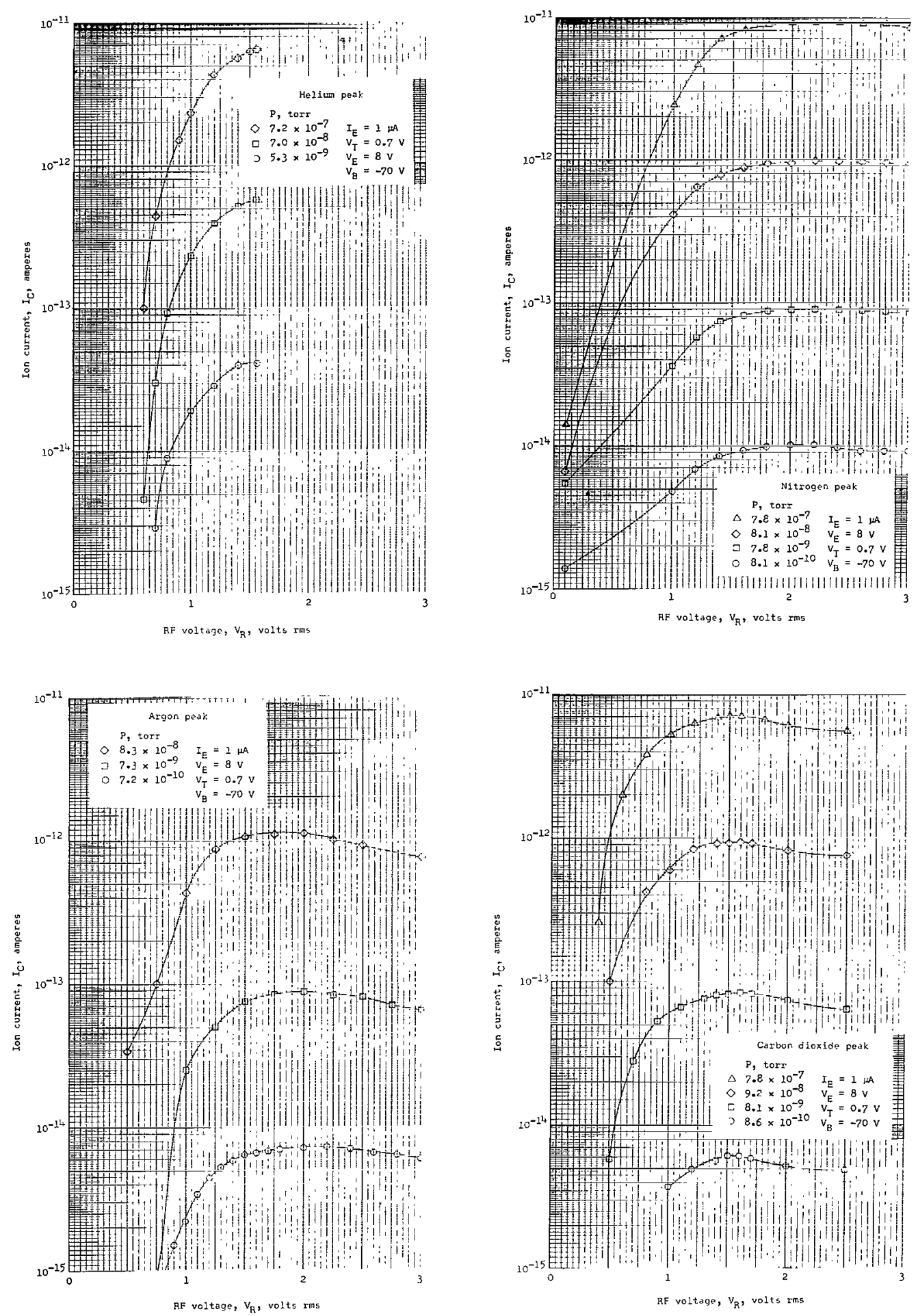

Figure 10.- Variation of ion current with RF voltage at various pressures. 




Figure 11.- Variation of ion current with RF voltage for argon at various emission currents. 




Figure 12. - Variation of ion current with trap voltage for argon at various emission currents. 


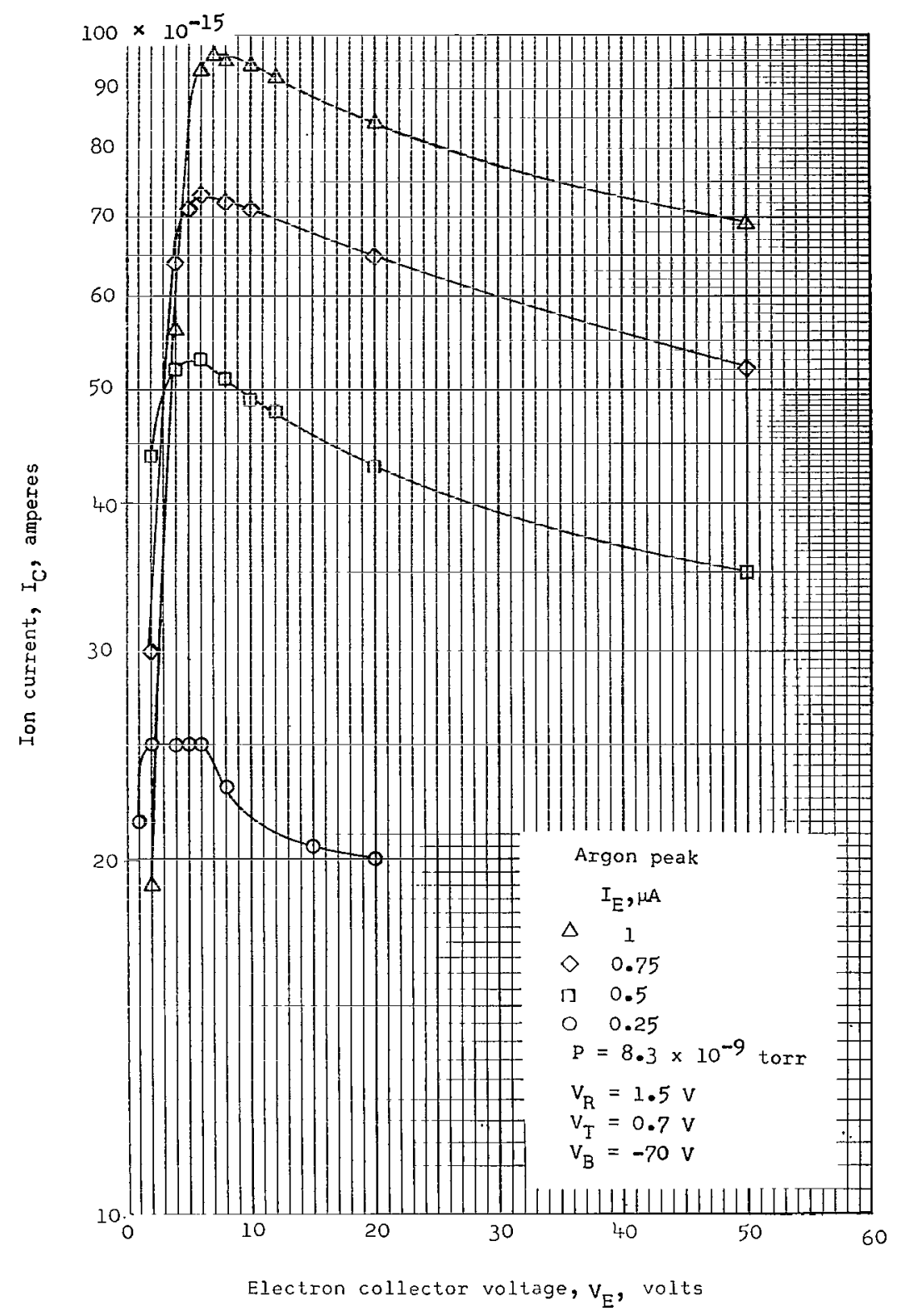

Figure 13. - Variation of ion current with electron collector voltage for argon at various emission currents. 


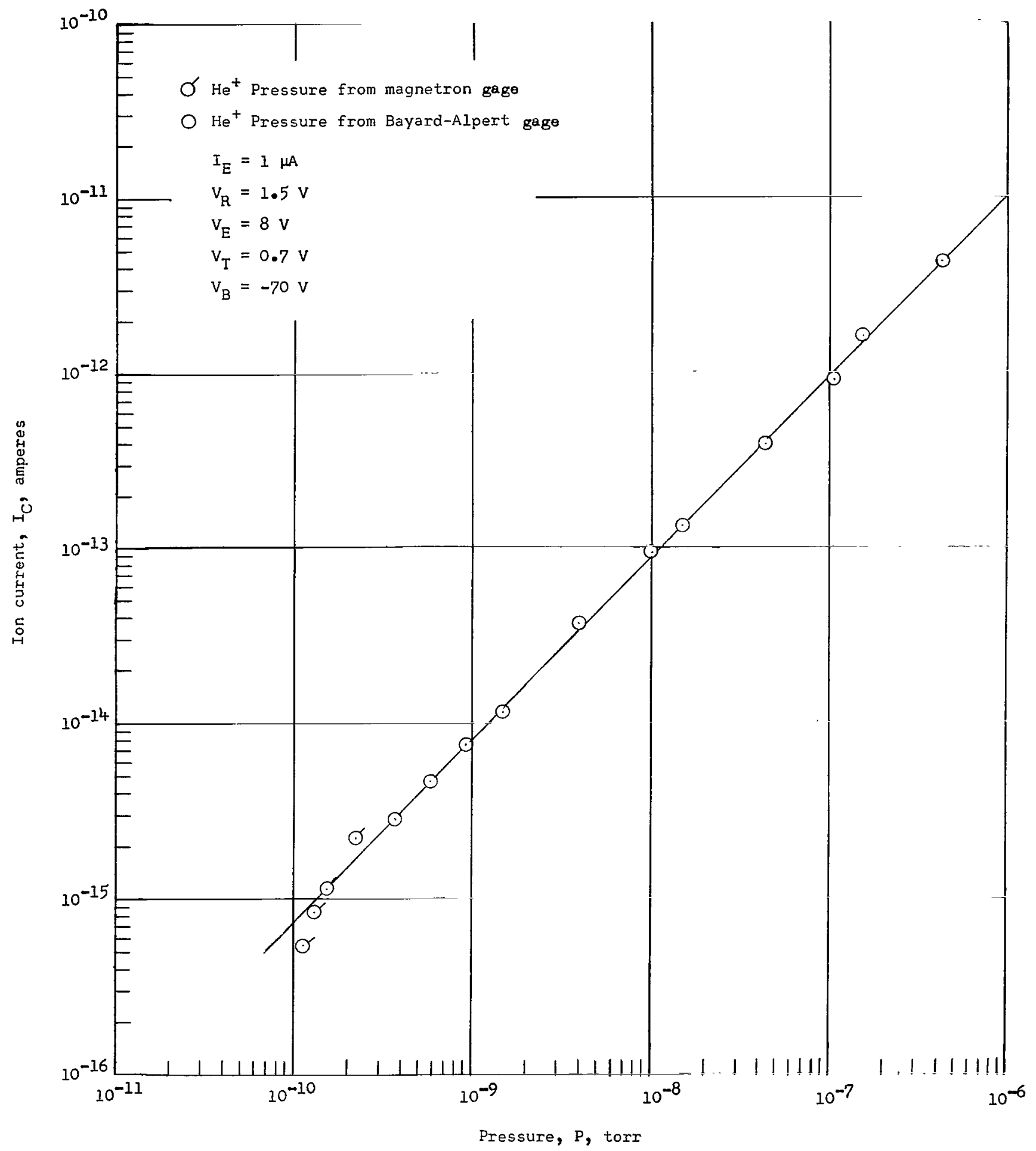

Figure 14.- Variation of ion current with pressure for helium. 


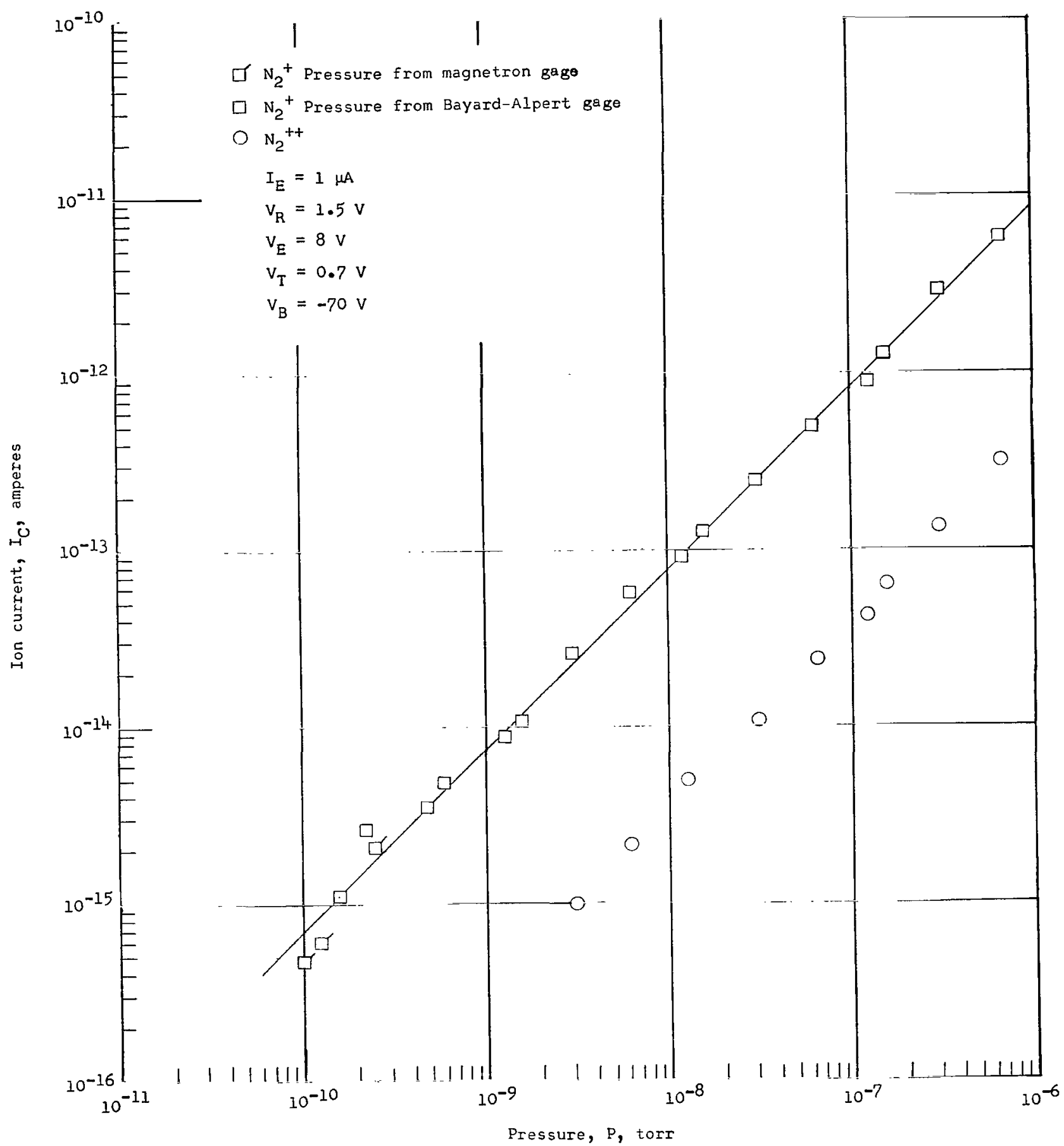

Figure 15.- Variation of ion current with pressure for nitrogen. 


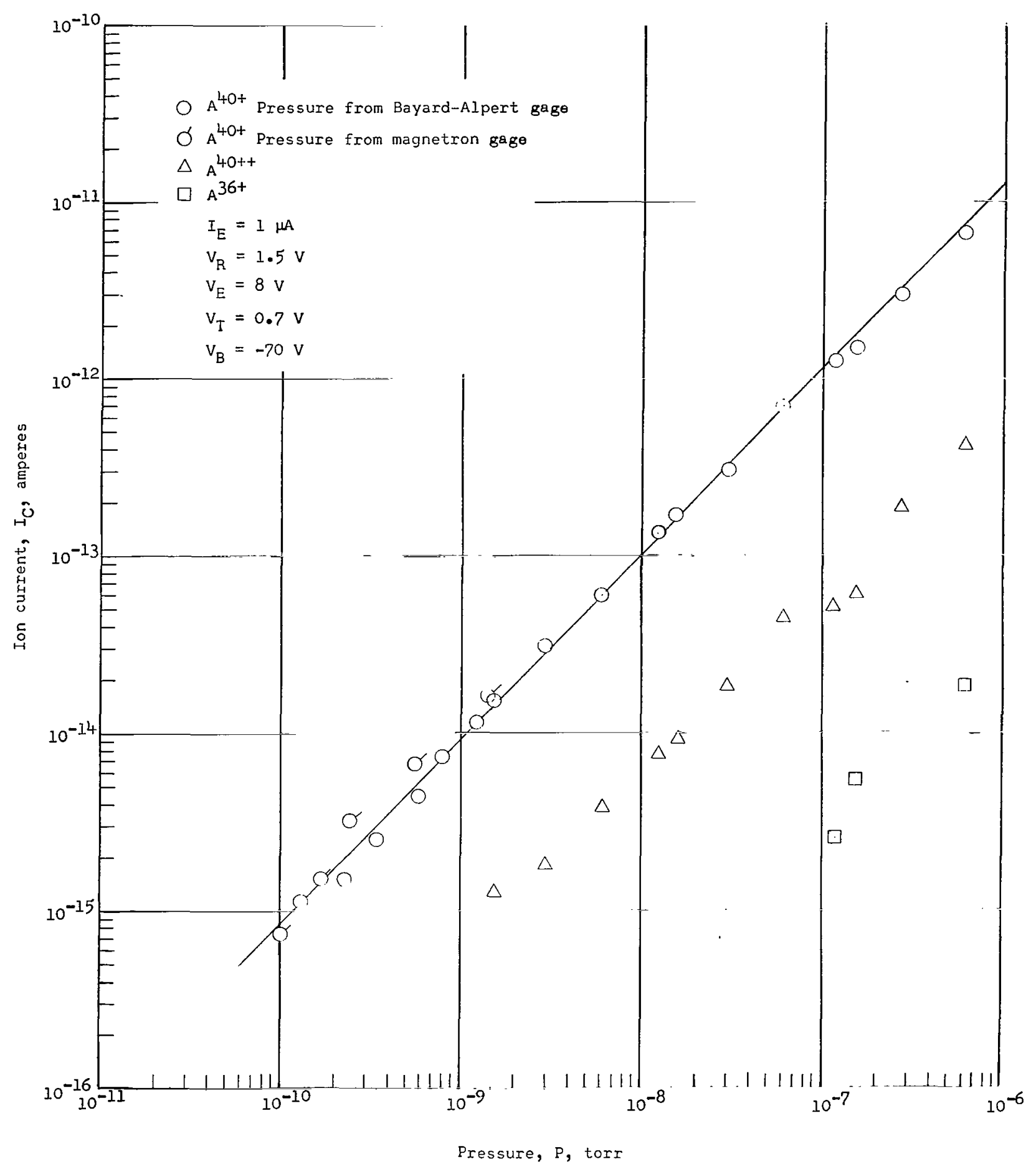

Figure 16. - Variation of ion current with pressure for argon. 


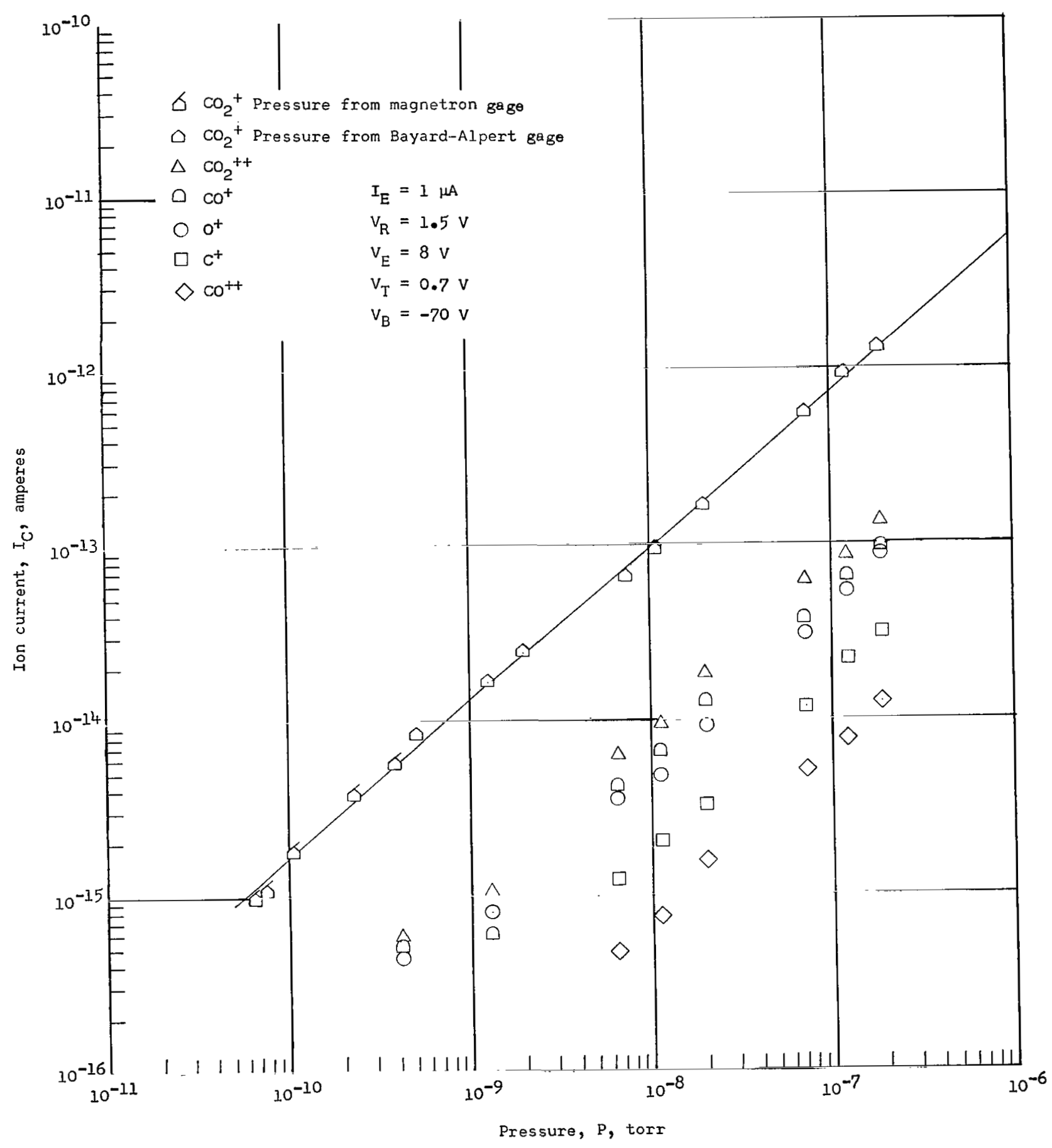

Figure 17.- Vartation of ion current with pressure for carbon dioxide. 

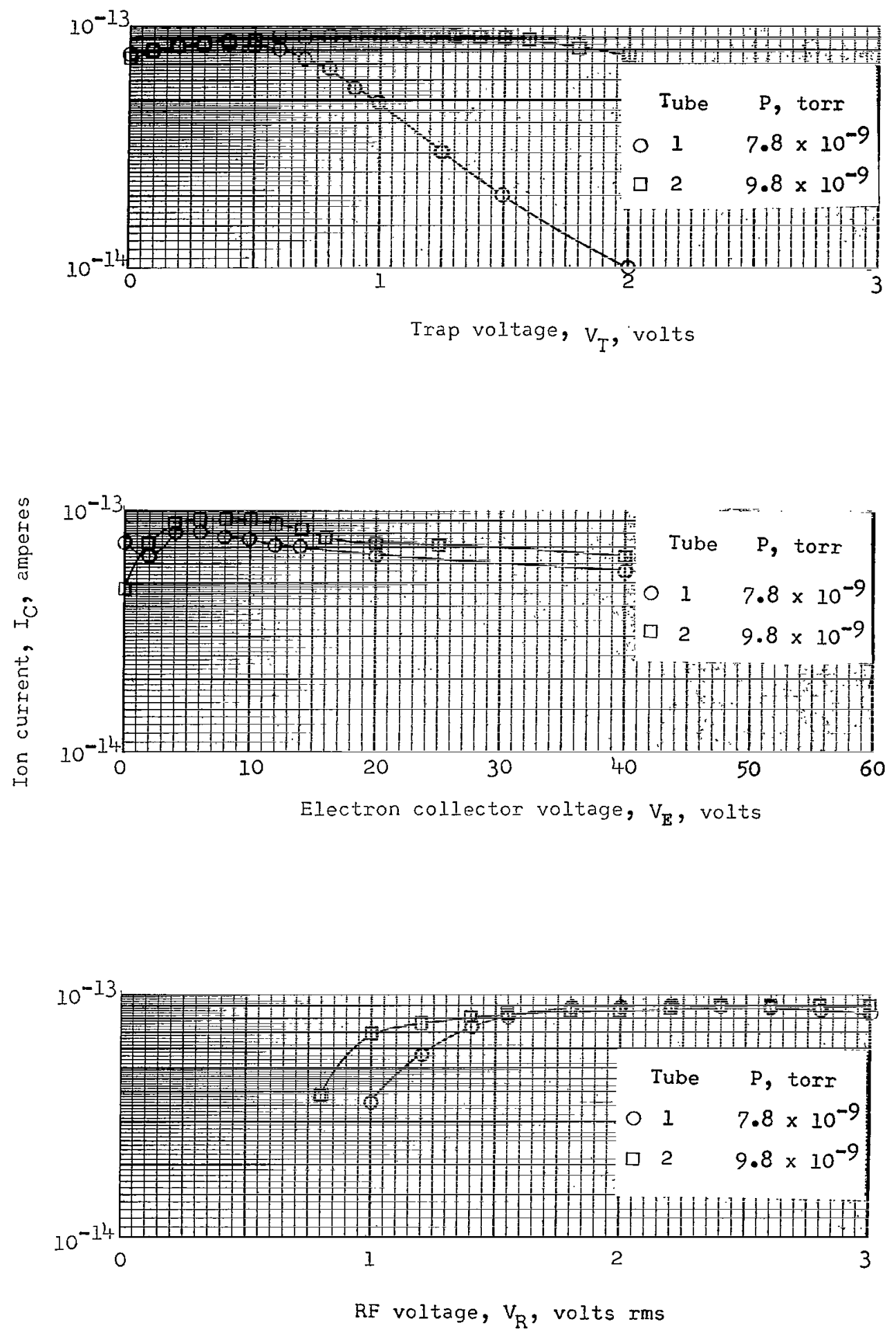

Figure 18.- Comparison of operating parameters for two omegatron tubes for nitrogen. 


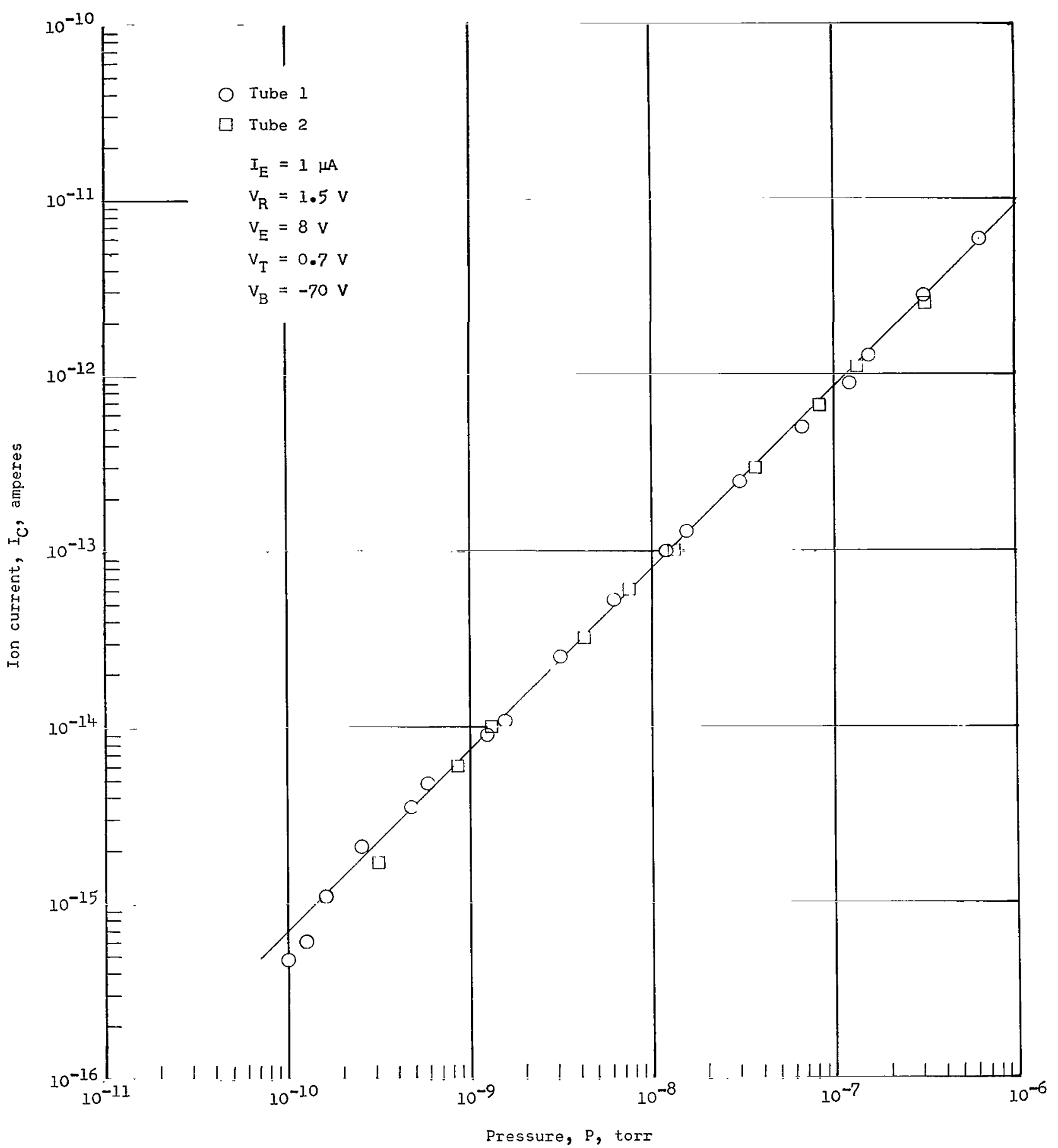

Figure 19.- Variation of ion current with pressure for two omegatron tubes for nitrogen. 


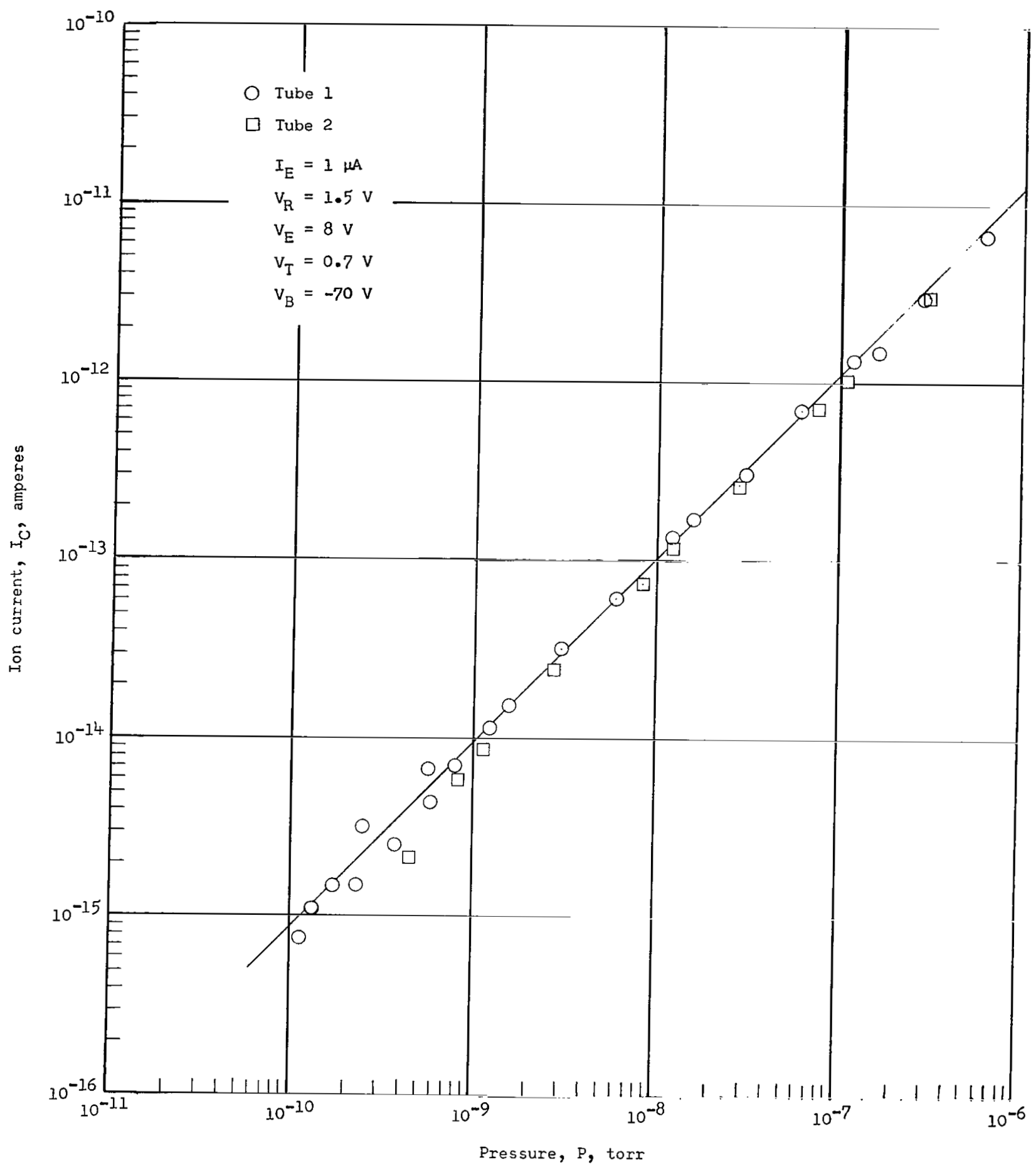

Figure 20.- Variation of ion current with pressure for two omegatron tubes for argon. 


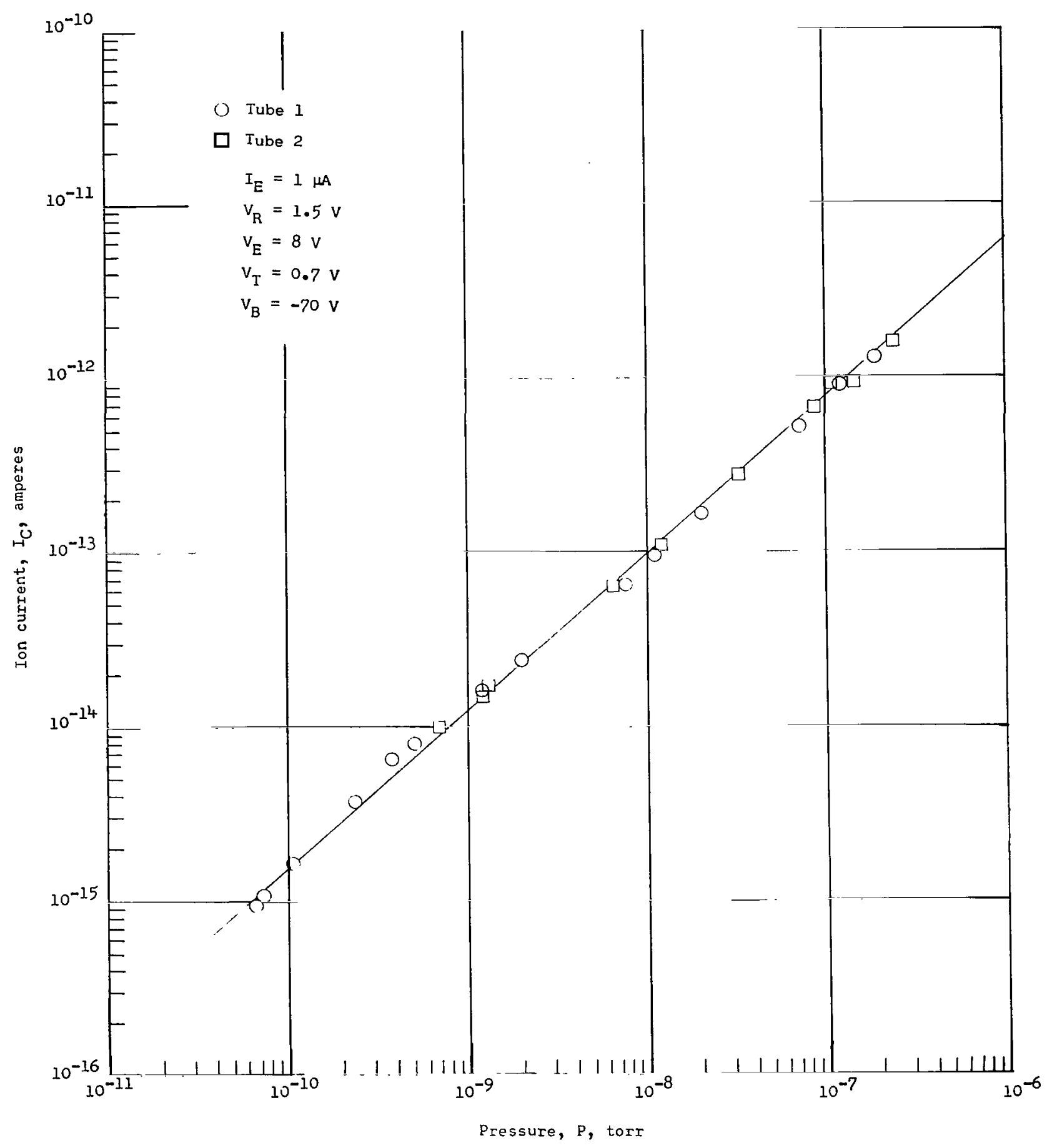

Figure 2l. - Variation of ion current with pressure for two omegatron tubes for carbon dioxide. 
"The aeronautical and space activities of the United States shall be conducted so as to contribute . . . to the expansion of buman knowledge of pbenomena in the atmosphere and space. The Administration shall provide for the widest practicable and appropriate dissemination of information conceming its activities and the results thereof."

-National Aeronautics and Space Act of 1958

\section{NASA SCIENTIFIC AND TECHNICAL PUBLICATIONS}

TECHNICAL REPORTS: Scientific and technical information considered important, complete, and a lasting contribution to existing knowledge.

TECHNICAL NOTES: Information less broad in scope but nevertheless of importance as a contribution to existing knowledge.

TECHNICAL MEMORANDUMS: Information receiving limited distribution because of preliminary data, security classification, or other reasons.

CONTRACTOR REPORTS: Technical information generated in connection with a NASA contract or grant and released under NASA auspices.

TECHNICAL TRANSLATIONS: Information published in a foreign language considered to merit NASA distribution in English.

TECHNICAL REPRINTS: Information derived from NASA activities and initially published in the form of journal articles.

SPECIAL PUBLICATIONS: Information derived from or of value to NASA activities but not necessarily reporting the results of individual NASA-programmed scientific efforts. Publications include conference proceedings, monographs, data compilations, handbooks, sourcebooks, and special bibliographies.

Details on the availability of these publications may be obtained from:

SCIENTIFIC AND TECHNICAL INFORMATION DIVISION

NATIONAL AERONAUTICS AND SPACE ADMINISTRATION

Washingłon, D.C. 20546 